\title{
CTCF is a Barrier for Totipotent-like Reprogramming
}

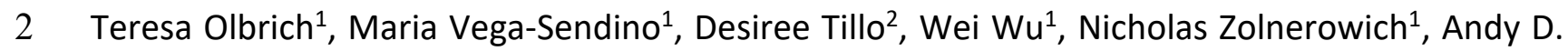

$3 \operatorname{Tran}^{3}$, Catherine N. Domingo ${ }^{1}$, Mariajose Franco', Marta Markiewicz-Potoczny ${ }^{1}$, Gianluca

4 Pegoraro ${ }^{4}$, Peter C. FitzGerald ${ }^{5}$, Michael J. Kruhlak ${ }^{3}$, Eros Lazzerini-Denchi ${ }^{1}$, Elphege P. Nora ${ }^{5,6}$,

$5 \quad$ Andre Nussenzweig ${ }^{1}$ and Sergio Ruiz ${ }^{1,7}$

6

$7 \quad{ }^{1}$ Laboratory of Genome Integrity, ${ }^{2}$ Genetics Branch, ${ }^{3}$ Laboratory of Cancer Biology and Genetics,

$8{ }^{4}$ Laboratory of Receptor Biology and Gene Expression and ${ }^{5}$ Genome Analysis Unit, $\mathrm{CCR}, \mathrm{NCl}, \mathrm{NIH}$,

9 Bethesda, MD, USA. ${ }^{5}$ Cardiovascular Research Institute, University of California San Francisco,

10 San Francisco, CA, 94143, USA. ${ }^{6}$ Department of Biochemistry and Biophysics, University of

11 California San Francisco, San Francisco, CA, 94143, USA.

12

$13 \quad{ }^{5}$ Lead Contact

14 Correspondence: sergio.ruizmacias@nih.gov 
SUMMARY:

24 Totipotent cells have the ability of generating embryonic and extra-embryonic tissues ${ }^{1,2}$.

25 Interestingly, a rare population of cells with totipotent-like potential was identified within ESC

26 cultures ${ }^{3}$. These cells, known as 2 cell (2C)-like cells, arise from ESC and display similar features

27 to those found in the totipotent 2 cell embryo ${ }^{2-4}$. However, the molecular determinants of $2 \mathrm{C}$ -

28 like conversion have not been completely elucidated. Here, we show that CTCF is a barrier for

29 2C-like reprogramming. Indeed, forced conversion to a 2 C-like state by DUX expression was

30 associated with DNA damage at a subset of CTCF binding sites. Endogenous or DUX-induced

31 2C-like ESC showed decreased CTCF enrichment at known binding sites, suggesting that

32 acquisition of a totipotent-like state is associated with a highly dynamic chromatin

33 architecture. Accordingly, depletion of CTCF in ESC efficiently promoted spontaneous and

34 asynchronous conversion to a totipotent-like state. This phenotypic reprogramming was

35 reversible upon restoration of CTCF levels. Furthermore, we showed that transcriptional

36 activation of the ZSCAN4 cluster was necessary for successful 2C-like reprogramming. In

37 summary, we revealed the intimate relation between CTCF and totipotent-like reprogramming. 
MAIN:

46 Totipotency is defined as the ability of a single cell to generate all cell types and is found in zygotes

47 and 2-cell (2C) embryos ${ }^{1,2}$. As development proceeds, embryonic cells progressively restrict their

48 developmental potential. Embryonic stem cells (ESC) isolated from the inner cell mass (ICM) of

49 blastocysts are defined as pluripotent since they lack the ability to differentiate into extra-

50 embryonic tissues ${ }^{1,2}$. Interestingly, a rare ( $\left.1-2 \%\right)$ transient population of cells with totipotent-

51 like potential was identified within ESC cultures ${ }^{2-4}$. This cell population expresses high levels of

52 transcripts detected in $2 \mathrm{C}$ embryos, including a specific gene set regulated by endogenous

53 retroviral promoters of the MERVL subfamily ${ }^{2-4}$. At the $2 \mathrm{C}$ embryonic stage, these retroviral

54 genetic elements are re-activated and highly expressed when the zygotic genome is first

55 transcribed and quickly silenced after further development. Based on this specific feature,

56 retroviral promoter sequences $(L T R)$ have been used as a reporter system to genetically label $2 \mathrm{C}$ -

57 like cells in vitro to study their behavior and properties ${ }^{2-4}$. Previous studies have shown the role

58 of different genes and pathways in converting ESC to a totipotent-like state in vitro ${ }^{3,4}$. Indeed,

59 expression of the transcription factor DUX in ESC is necessary and sufficient to induce a 2C-like

60 conversion characterized by similar transcriptional and chromatin accessibility profiles, including

61 MERVL activation, as observed in 2 C-blastomeres ${ }^{5-7}$. This reprogramming cell model has been

62 instrumental to study the molecular mechanisms that regulate the acquisition and maintenance

63 of totipotent-like features. DUX belongs to the double homeobox family of transcription factors

64 exclusive to placental mammals ${ }^{8}$ and is expressed exclusively in the $2 \mathrm{C}$ embryo $\mathrm{o}^{5-7}$. Interestingly,

65 DUX knockout mice revealed that DUX is important but not essential for development, suggesting 
66 that additional mechanisms regulate zygotic genome activation (ZGA) and the associated

67 totipotent state in vivo ${ }^{9,10}$.

\section{C-like conversion correlates with DNA damage and cell death}

70 To explore new molecular determinants regulating totipotency, we generated ESC carrying a

71 doxycycline (DOX)-inducible DUX cDNA (hereafter, ESC $\left.{ }^{\text {Dux }}\right)^{11}$. Upon DOX activation we detected

72 the expected expression of Dux and its downstream ZGA-associated genes (Extended data Fig.

73 1a, b). In addition, ESCDux containing an LTR-RFP reporter showed reactivation of MERVL

74 sequences after DOX induction (Extended data Fig. 1c, d). Over-expression of DUX triggers

75 toxicity in myoblasts ${ }^{12}$. However, whether sustained expression of DUX leads to cell death in ESC

76 has not been explored thoroughly. We observed that DUX expression induced cell death in a dose

77 and time-dependent manner and correlated with the extent of 2C-like conversion (Fig. 1a).

78 Indeed, live cell imaging of DOX-treated ESC Dux expressing H2B-eGFP showed efficient cell death

79 in cells asynchronously converting to a 2C-like state (Fig. 1b, Supplementary Video 1).

80 Interestingly, accumulation of DOX-induced ESC Dux in the G1 and G2 phases of the cell cycle along

81 with a decrease in DNA replication preceded cell death (Fig. 1c, d). To exclude that these effects

82 were due to supra-physiological levels of DUX, we analyzed the unperturbed subpopulation of

83 ESC that spontaneously undergoes a 2C-like conversion ${ }^{3}$. These endogenous totipotent-like ESC

84 were also characterized by G2 accumulation, decreased DNA replication, and overt spontaneous

85 cell death following 2C-like conversion (Extended data Fig. 2a-c and Supplementary Video 2). In

86 support of these observations, the activation of the transcriptional $2 \mathrm{C}$ program during ZGA 
87 following the first cleavage in fertilized zygotes is accompanied by an extremely long G2 phase

88 (around 12-16 hours) ${ }^{13,14}$.

89 We next examined whether G2 accumulation correlated with DUX-induced DNA damage. We

90 observed that sustained expression of DUX leads to DNA-damage, revealed by the increased

91 levels of phosphorylated $\mathrm{H} 2 \mathrm{AX}(\gamma \mathrm{H} 2 \mathrm{AX})$ and KRAB-associated protein 1 (KAP1) in a dose and time-

92 dependent manner (Fig. 1e, f). We also detected higher levels of $\gamma \mathrm{H} 2 \mathrm{AX}$ in endogenous 2C-like

93 ESC (Extended data Fig. 2d). The decrease in DNA replication and elevated levels of $\gamma H 2 A X$

94 observed in 2C-like ESC suggested that replication stress (RS) could underlie the increased levels

95 of DNA damage in these cells. Accordingly, increasing RS levels by using an ATR inhibitor showed

96 an additive effect of RS and DUX expression on DNA damage (Fig. 1g). Our results showed that

97 induction of a totipotent-like state in ESC induced G2 accumulation and decreased cell viability

98 associated with replication stress-mediated DNA-damage.

100 Reduced levels of chromatin bound CTCF in 2C-like ESC

101 We next sought to investigate the nature of the DNA damage. Since DUX is a potent

102 transcriptional activator, we hypothesized that RS-induced DNA damage was localized in specific

103 regions of the genome rather than being randomly distributed. To explore this possibility, we

104 performed END-seq ${ }^{15}$, a highly sensitive method to detect DNA ends (single or double strand

105 breaks) genome-wide at base-pair resolution. DUX-expressing ESC showed increased

106 accumulation of ENDseq signal compared to untreated ESC Dux (Fig. 2a). A total of 1539 ENDseq

107 peaks overlapped between two independent ESC ${ }^{\text {Dux }}$ clones (Supplementary Tables 1-3).

108 Moreover, the type of lesion (double or single strand DNA break) at each site, showed high 
109 correlation when both ESC $^{\text {Dux }}$ clones were compared (Extended data Fig. 3a-c). More than 25\%

110 of the ENDseq peaks localized within a $10 \mathrm{~kb}$ distance from a DUX binding site. Furthermore, 16\%

111 of the 1220 genes associated by proximity to ENDseq peaks, including well-known 2C genes, were

112 strongly upregulated by DUX (Extended data Fig. 3d and Supplementary Tables 4, 5). These

113 results showed that DUX-induced 2C-like conversion reproducibly generated DNA lesions in

114 specific genomic regions associated with DUX-induced transcription. We next asked whether

115 these regions shared any feature that could explain the reiterative DNA damage on them. Thus,

116 we performed a transcription factor motif enrichment analysis using our END-seq peak dataset

117 and found the CTCF binding motif as one of the most significant (Extended data Fig. 3e). Using

118 published CTCF ChIPseq datasets in $\mathrm{ESC}^{16}$, we confirmed that around $50 \%$ of the END-seq peaks

119 were occupied by CTCF (Fig. 2b, c, Extended data Fig. 3c, f, g and Supplementary table 6).

120 Moreover, these sites were also enriched in SMC1 and SMC $3^{17}$, components of the cohesin ring-

121 like protein complex (Fig. 2b, c, Extended data Fig. 3f).

122 The transcription factor CTCF is a zinc-finger binding protein involved in chromosome folding and

123 insulation of topologically associated domains (TADs) $)^{18}$. Based on the observed CTCF-associated

124 DNA damage in DOX-induced ESC ${ }^{\text {Dux }}$, we speculated that CTCF might represent a barrier for the

125 reprogramming to totipotency. This idea was supported by two observations. First, cohesin

126 depletion in differentiated cells facilitates reprogramming during somatic cell nuclear transfer by

127 activating $\mathrm{ZGA}^{19}$. Second, totipotent zygotes and 2C embryos are characterized by chromatin in

128 a relaxed state associated with weak TADs ${ }^{20-21}$. Following fertilization, development is

129 accompanied by a progressive maturation of high-order chromatin architecture ${ }^{20-21}$.

130 Interestingly, increasing levels of CTCF during human ED are required for the progressive 
131 establishment of TADs ${ }^{22}$. Similarly, we also observed a steady increase in the levels of CTCF during

132 development in mouse embryos (Extended data Fig. 4). To examine whether levels of chromatin-

133 bound CTCF correlated with totipotency features, we first assessed the CTCF binding landscape

134 in 2C-like cells by native Cut\&Run sequencing. For this, we used $L T R-R F P$ reporter ESC ${ }^{\text {DUX }}$ to first

135 induce 2C-like conversion, and then, sort $\mathrm{RFP}^{+}$and RFP- cells at two different timepoints, 16 and

13624 hours after DOX induction (Fig. 2d-f). Interestingly, 16 hours after DOX induction, RFP- ESC

137 showed a slight increased CTCF enrichment at known CTCF sites ${ }^{20}$ compared to non-induced ESC

138 while $\mathrm{RFP}^{+}$showed the opposite trend (Fig. 2e, f). Changes in CTCF enrichment were further

139 enhanced in cells reprogrammed 24 hours after DUX expression (Fig. 2e, f) and were not due to

140 variations in the total levels of CTCF (Fig. 2g). Significantly, spontaneously converting 2C-like ESC

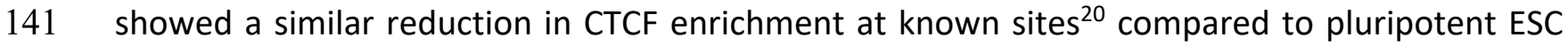

142 (Extended data Fig. 5). Combined, these results demonstrated that totipotent-like cells are

143 characterized by decreased levels of chromatin-bound CTCF, indicative of a more relaxed

144 chromatin architecture.

\section{CTCF depletion leads to spontaneous 2C-like conversion}

147 To examine whether reduced levels of CTCF enrichment are causative for acquiring totipotency-

148 like features, we used an auxin-inducible degron system to deplete CTCF in ESC ${ }^{23}$. This cell line 149 (ESC ${ }^{\text {CTCF-AID }}$ hereafter) harbors both Ctcf alleles tagged with an auxin-inducible degron (AID) ${ }^{24}$

150 sequence fused to eGFP. Although CTCF-AID protein levels in ESC CTCF-AID are lower compared to

151 untagged CTCF in wild-type cells, ESC CTCF-AID showed negligible transcriptional changes as tagged

152 CTCF retains most functionality ${ }^{23}$. To test whether CTCF deletion induces conversion to 2C-like 
153 cells we first examined in CTCF-depleted cells the expression levels of the zinc finger protein

154 ZSCAN4, a gene cluster that is selectively expressed in 2C embryos and 2C-like ESC ${ }^{3,25}$. Strikingly,

155 ZSCAN4 levels were elevated two days following CTCF depletion and further increased two days

156 later (Fig. 3a and Extended data Fig. 6a, b). Indeed, more than 20\% of the cells expressed ZSCAN4

157 three days following CTCF depletion (Extended data Fig. 6b). Importantly, similar percentages of

$158 \mathrm{RFP}^{+}$cells were observed in LTR-RFP reporter ESC CTCF-AID (Fig. 3b). This percentage decreased upon

159 restoration of the CTCF levels by washing off auxin (Fig. 3b). Using RNAseq datasets from CTCF-

160 depleted cells at different timepoints, we observed a progressive increase in the expression of

161 genes enriched or exclusively expressed in 2C embryos or 2C-like ESC (Fig. 3c, d and

162 Supplementary Table 7). Among these, endogenous MERVL sequences as well as Dux were

163 selectively expressed over time upon CTCF depletion (Fig. 3d). We also observed decreased

164 expression of the pluripotent gene OCT4 in ZSCAN4+ auxin-treated ESC ${ }^{\text {CTCF-AID }}$ as described for 2C-

165 like ESC (Fig. 3e) ${ }^{5}$. Furthermore, CTCF-depleted ESC showed transcriptional similarity with DUX-

166 overexpressing ESC (Extended data Fig. 6c). In addition, 2C-like reprogramming was further

167 boosted cooperatively by expressing low levels of DUX or by incubating ESC ${ }^{\text {CTCF-AID }}$ with HDAC

168 inhibitors, known to promote 2C-like conversion (Extended data Fig. 6d, e). Finally, we validated

169 these observations by generating additional ESC ${ }^{\text {CTCF-AID }}$ clonal lines (Extended data Fig. 6f).

170 Collectively, these results demonstrated that CTCF depletion leads to spontaneous 2C-like

171 conversion in ESC.

172 We next examined the dynamics of the 2C-like conversion by live cell imaging in LTR-RFP reporter

173 ESC CTCF-AID. Reprogramming to 2C-like ESC is asynchronous as ESC convert over time after CTCF

174 depletion (Fig. 3f). Interestingly, we observed that spontaneously converted 2C-like ESC undergo 
175 similar cell death as shown for endogenous 2C-like ESC while non-converted ESC divide and do

176 not show overt cell death (Fig. 3f, Supplementary Video 3). Accordingly, CTCF-depleted 2C-like

177 ESC showed increased $\gamma \mathrm{H} 2 \mathrm{AX}$, similar to endogenous 2C-like ESC (Extended data Fig. 6g). Our data

178 suggested that cell toxicity induced by CTCF-depletion is due to the selective death of the

179 spontaneously converted 2C-like ESC. Finally, we explored whether restoring CTCF expression

180 facilitates the exit from the totipotent-like state. For this, CTCF-depleted LTR-RFP reporter

181 ESC CTCF-AID for four days were either further incubated with auxin or washed off for an additional

18218 hours (5 days total) and sorted based on RFP expression. Gene expression analysis showed

183 that restoration of CTCF levels induced a decrease in the 2C-like transcriptional program in 2C-

184 like cells anticipating the exit from the totipotent-like state (Fig. 3g and Extended data Fig. 7).

185 Collectively, these results demonstrated that chromatin bound CTCF prevents 2C-like conversion.

\section{ZSCAN4 expression is required for 2C-like reprogramming}

188 Endogenous emergence of 2C-like cells in ESC cultures is a stepwise process defined by sequential

189 changes in gene expression ${ }^{26}$. ZSCAN4 ${ }^{+}$MERVL $^{-}$ESC are detected during this process and

190 represent an intermediate step that precedes the full conversion to a 2C-like state ${ }^{26,27}$. Levels of

191 ZSCAN4 progressively increase during 2C conversion prior to the activation of MERVL sequences

192 and the expression of chimeric transcripts ${ }^{26,27}$. We also detected a progressive accumulation of

193 ZSCAN4 in CTCF-depleted ESC starting as early as 24 hours after depletion (Fig. 4a and Extended

194 data Fig. 8a, b). However, upregulation of DUX or MERVL sequences was observed at later

195 timepoints, suggesting that spontaneous conversion upon CTCF depletion followed a similar

196 molecular roadmap as endogenous 2C-like cells. In agreement, we also detected ZSCAN4 ${ }^{+} \mathrm{mERVL}^{-}$ 
197 ESC in early auxin treated LTR-RFP reporter ESC ${ }^{\text {CTCF-AID }}$ (Extended data Fig. 8c). We next asked

198 whether early transcriptional activation of ZSCAN4 in ESC precursors is essential for full

199 conversion to 2 C-like cells. Therefore, we infected $L T R$-RFP reporter ESC CTCF-AID with lentiviruses

200 expressing shRNAs against ZSCAN4 and examined transcriptional dynamics and 2C-like

201 conversion upon CTCF removal ${ }^{28}$. Surprisingly, downregulation of ZSCAN4 in CTCF-depleted cells

202 impaired expression of 2C markers and abrogated reprogramming to 2C-like cells (Fig. 4b, c and

203 Extended data Fig. 8d). Furthermore, over-expression of ZSCAN4C boosted 2C-like conversion as

204 early as 24 hours specifically in CTCF-depleted ESC while cells with normal levels of CTCF did not

205 show major changes in the number of 2C-like cells (Fig. $4 \mathrm{~d}$ and Extended data Fig. 8e). These

206 combined results demonstrated that ZSCAN4 proteins are essential for the 2C-like conversion

207 mediated by CTCF depletion.

\section{DISCUSSION}

210 Our study demonstrates that 2C-like ESC are unstable in vitro. We observed increased DNA

211 damage and cell death in endogenous, DUX-induced and CTCF-depleted 2C-like ESC. Similarly,

212 over-expression of DUX in vivo leads to developmental arrest and embryo death ${ }^{29}$. We show that

213 the DNA damage observed in DUX-induced 2C-like ESC might be at least partially associated to

214 replication stress and involves the generation of single or double strand brakes at certain CTCF

215 sites. We speculate that proximity of ENDseq peaks to DUX-binding sites might induce local de

216 novo transcription/replication conflicts. Inefficient release of nearby bound CTCF in ESC

217 undergoing 2C-like conversion could promote fork stalling and eventual breakage. Further work

218 will be needed to understand the exact origin of these DNA breaks. Nevertheless, additional 
219 sources of damage are likely to be associated with the 2C-like state or induced by DUX. In fact,

220 human ortholog DUX4 mediates the accumulation of dsRNA foci and the activation of the dsRNA

221 response contributing to the apoptotic phenotype associated with DUX over-expression ${ }^{30}$.

222 CTCF depletion triggers spontaneous 2C-like conversion and promotes the acquisition of

223 totipotent-like features in ESC (Fig. 4e). Importantly, expression of the ZSCAN4 gene cluster is a

224 necessary early event in this conversion and, although its precise role in this process is unclear,

225 ZSCAN4 has been implicated in protecting the 2C embryo from DNA damage ${ }^{28,31}$. Thus, ZSCAN4

226 could participate in limiting the damage associated with the 2C-like conversion. Expression of

227 DUX, which is a later event, enhances the transcriptional activation of the ZSCAN4 cluster by

228 direct DUX binding to its promoters. In fact, DUX knockout ESC and embryos showed defective

229 ZSCAN4 activation. This positive feedback loop might be required to stabilize the 2C-like state ${ }^{9-}$

$230 \quad 10$.

231 Totipotent cells display high core histone mobility compared to pluripotent cells ${ }^{32,33}$. Similarly,

232 our results indicate that totipotency is associated with dynamic chromatin architecture

233 characterized by decreased levels of chromatin-bound CTCF. CTCF binds to a large number of

234 endogenous RNAs and this interaction seems important for chromatin CTCF deposition ${ }^{34}$. Indeed,

235 CTCF mutants unable to bind RNA showed decreased genome-wide binding ${ }^{34}$. It is tempting to

236 speculate that the progressive strength of TADs during ED ${ }^{20-21}$ correlates with increasing levels of

237 CTCF and RNA transcription after ZGA. Further work will be needed to address how CTCF

238 deposition and TAD insulation take place during early development and if these events play an

239 active role in promoting the exit from totipotency in the early embryo. In summary, we revealed

240 the intertwined relation between CTCF and totipotent-associated features. 


\section{REFERENCES}

$2431 \mathrm{Lu}, \mathrm{F}$. and Y. Zhang. Cell totipotency: molecular features, induction, and maintenance. Natl. Sci.

244 Rev. 2, 217-225 (2015).

2462 Riveiro, A.R. and Brickman, J.M. From pluripotency to totipotency: an experimentalist's guide

247 to cellular potency. Development 147, dev189845 (2020).

2493 Macfarlan, T.S., Gifford WD, Driscoll S, Lettieri K, Rowe HM, Bonanomi D, Firth A, Singer O,

250 Trono D, Pfaff SL. Embryonic stem cell potency fluctuates with endogenous retrovirus activity.

$251 \quad$ Nature 487, 57-63 (2012).

2534 Genet, M. and Torres-Padilla, M.E. The molecular and cellular features of 2-cell-like cells: a 254 reference guide. Development 147, dev189688 (2020).

2565 Hendrickson, P.G., Doráis J.A., Grow, E.J., Whiddon, J.L., Lim, J.W., Wike, C.L., Weaver, B.D.,

257 Pflueger, C., Emery, B.R., Wilcox, A.L., Nix, D.A., Peterson, C.M., Tapscott. S.J., Carrell, D.T. and 258 Cairns, B.R. Conserved roles of mouse DUX and human DUX4 in activating cleavage-stage genes 259 and MERVL/HERVL retrotransposons. Nat. Genet. 49, 925-934 (2017). 
2616 De Iaco, A., Planet, E., Coluccio, A., Verp, S., Duc, J. and Trono D. DUX-family transcription

262 factors regulate zygotic genome activation in placental mammals. Nat. Genet. 49: 941-945

263 (2017).

264

2657 Whiddon, J.L., Langford, A.T., Wong, C.J., Zhong, J.W. and Tapscott, S.J. Conservation and

266 innovation in the DUX4-family gene network. Nat. Genet. 49, 935-940 (2017).

2688 Leidenroth, A. and Hewitt, J.E. A family history of DUX4: phylogenetic analysis of DUXA, B, C 269 and Duxbl reveals the ancestral DUX gene. BMC Evol. Biol. 10, 364 (2010).

2719 Chen, Z. and Zhang, Y. Loss of DUX causes minor defects in zygotic genome activation and is 272 compatible with mouse development. Nat. Genet. 51, 947-951 (2019).

27410 De laco, A., Verp, S., Offner, S., Grun, D. and Trono, D. DUX is a non-essential synchronizer of 275 zygotic genome activation. Development 147, dev.177725 (2019).

27711 Beard, C., Hochedlinger, K., Plath, K., Wutz, A., and Jaenisch, R. Efficient method to generate 278 single-copy transgenic mice by site-specific integration in embryonic stem cells. Genesis 44, 2327928 (2006). 
28112 Eidahl, J.O., Giesige, C.R., Domire, J.S., Wallace, L.M., Fowler, A.M., Guckes, S.M., Garwick-

282 Coppens, S.E., Labhart, P. and Harper, S.Q. Mouse Dux is myotoxic and shares partial functional

283 homology with its human paralog DUX4. Hum. Mol. Genet. 25, 4577-4589 (2016).

28513 Gamo, E.I. and Prescott, D.M. The cell life cycle during early embryogenesis of the mouse. Exp

286 Cell Res. 59, 117-23 (1970).

14 Luthardt, F.W. and Donahue, R.P. DNA synthesis in developing two-cell mouse embryos. Dev.

Bio./ 44, 210-6 (1975).

15 Canela, A., Sridharan, S., Sciascia, N., Tubbs, A., Meltzer, P., Sleckman, B.P. and Nussenzweig,

A. DNA Breaks and End Resection Measured Genome-wide by End Sequencing. Mol. Cell 63, 898-

911 (2016).

16 Beagan, J.A., Duong, M.T., Titus, K.R., Zhou, L., Cao, Z., Ma, J., Lachanski, C.V., Gillis, D.R. and

297 lineage commitment. Genome Res. 27, 1139-1152 (2017).

17 Kagey, M.H., Newman, J.J., Bilodeau, S., Zhan, Y., Orlando, D.A., van Berkum, N.L., Ebmeier,

300 C.C., Goossens, J., Rahl, P.B., Levine, S.S., Taatjes, D.J., Dekker, J. and Young, R.A. Mediator and

301 cohesin connect gene expression and chromatin architecture. Nature 467, 430-435 (2010). 
18 Ghirlando, R. and Felsenfeld, G. (2016) CTCF: making the right connections. Genes Dev. 30, 881-891.

19 Zhang, K., Wu, D.Y., Zheng, H., Wang, Y., Sun, Q.R., Liu, X., Wang, L.Y., Xiong, W.J., Wang, Q.,

Rhodes, J.D.P., Xu, K., Li, L., Lin, Z., Yu, G., Xia, W., Huang, B., Du, Z., Yao, Y., Nasmyth, K.A., Klose,

Cohesin in Impeding Minor ZGA. Mol. Cell 79, 234-250 (2020).

31120 Ke, Y., Xu, Y., Chen, X., Feng, S., Liu, Z., Sun, Y., Yao, X., Li, F., Zhu, W., Gao, L., Chen, H., Du, Z.,

312 Xie, W., Xu, X., Huang, X. and Liu, J. 3D Chromatin Structures of Mature Gametes and Structural

313 Reprogramming during Mammalian Embryogenesis. Cell 170, 367-381 (2017).

31521 Du, Z., Zheng, H., Huang, B., Ma, R., Wu, J., Zhang, X., He, J., Xiang, Y., Wang, Q., Li, Y., Ma, J.,

316 Zhang, X., Zhang, K., Wang, Y., Zhang, M.Q., Gao, J., Dixon, J.R., Wang, X., Zeng, J. and Xie W.

317 Allelic reprogramming of 3D chromatin architecture during early mammalian development.

318 Nature 547, 232-235 (2017).

32022 Chen, X., Ke, Y., Wu, K., Zhao, H., Sun, Y., Gao, L., Liu, Z., Zhang, J., Tao, W., Hou, Z., Liu, H., Liu,

321 J. and Chen, Z.J. Key role for CTCF in establishing chromatin structure in human embryos. Nature

$322576,306-310$ (2019). 
32423 Nora, E.P., Goloborodko, A., Valton, A.L., Gibcus, J.H., Uebersohn, A., Abdennur, N., Dekker,

325 J., Mirny, L.A. and Bruneau, B.G. Targeted Degradation of CTCF Decouples Local Insulation of

326 Chromosome Domains from Genomic Compartmentalization. Cell 169, 930-944 (2017).

32824 Nishimura, K., Fukagawa, T., Takisawa, H., Kakimoto, T. and Kanemaki, M. An auxin-based

329 degron system for the rapid depletion of proteins in nonplant cells. Nat. Methods 6, 917-922

330 (2009).

33225 Falco, G., Lee, S.-L., Stanghellini, I., Bassey, U. C., Hamatani, T. and Ko, M. S. H. Zscan4: A

333 novel gene expressed exclusively in late 2-cell embryos and embryonic stem cells. Dev. Biol.

$334307,539-550$ (2007).

33626 Rodriguez-Terrones, D., Gaume, X., Ishiuchi, T., Weiss, A., Kopp, A., Kruse, K., Penning, A.,

337 Vaquerizas, J.M., Brino, L. and Torres-Padilla, M.E. A molecular roadmap for the emergence of 338 early-embryonic-like cells in culture. Nat. Genet. 50, 106-119 (2018).

34027 Fu, X., Djekidel, M.N. and Zhang, Y. A transcriptional roadmap for 2C-like-to-pluripotent state

341 transition. Sci Adv. 6, eaay5181 (2020).

34328 Markiewicz-Potoczny, M., Lobanova, A., Loeb, A.M. et al. TRF2-mediated telomere protection

344 is dispensable in pluripotent stem cells. Nature (2020). https://doi.org/10.1038/s41586-020- 
34729 Guo, M., Zhang, Y., Zhou, J., Bi, Y., Xu, J., Xu, C., Kou, X., Zhao, Y., Li, Y., Tu, Z., Liu, K., Lin, J.,

348 Yang, P., Gao, S. and Wang, Y. Precise temporal regulation of Dux is important for embryo

349 development. Cell Res. 29, 956-959 (2019).

35130 Shadle, S.C., Bennett, S.R., Wong, C.J., Karreman, N.A., Campbell, A.E., van der Maarel, S.M., 352 Bass, B.L. and Tapscott, S.J. DUX4-induced bidirectional HSATII satellite repeat transcripts form 353 intranuclear double-stranded RNA foci in human cell models of FSHD. Hum. Mol. Genet. 28, 39973544011 (2019).

31 Srinivasan, R., Nady, N., Arora, N., Hsieh, L.J., Swigut, T., Narlikar, G.J., Wossidlo, M. and Wysocka. Zscan4 binds nucleosomal microsatellite DNA and protects mouse two-cell embryos from DNA damage. J. Sci. Adv. 6, eaaz9115. (2020)

36433 Ooga, M., Fulka, H., Hashimoto, S., Suzuki, M.G. and Aoki, F. Analysis of chromatin structure 365 in mouse preimplantation embryos by fluorescent recovery after photobleaching. Epigenetics 11: 85-94 (2016). 
bioRxiv preprint doi: https://doi.org/10.1101/2020.12.20.423692; this version posted December 22, 2020. The copyright holder for this preprint

(which was not certified by peer review) is the author/funder, who has granted bioRxiv a license to display the preprint in perpetuity. It is made available under aCC-BY-NC-ND 4.0 International license.

36834 Saldaña-Meyer, R., Rodriguez-Hernaez, J., Escobar, T., Nishana, M., Jácome-López, K., Nora,

369 E.P., Bruneau, B.G., Tsirigos, A., Furlan-Magaril, M., Skok, J. and Reinberg D. RNA Interactions Are

370 Essential for CTCF-Mediated Genome Organization. Mol. Cell. 76, 412-422 (2019).

371

372

373

374

375

376

377

378

379

380

381

382

383

384

385

386

387

388

389 
METHODS

392 Embryo Culture

393 C57BL/6J mice were obtained from the Jackson Laboratory. All the animal work included here 394 was performed in compliance with the NIH Animal Care \& Use Committee (ACUC) Guideline for 395 Breeding and Weaning. For embryo isolation, 4-weeks old female mice were injected 396 intraperitoneally with 5IU Pregnant Mare Serum Gonadotropin (PMSG, Prospec) followed by 5 397 IU human Chorionic Gonadotropin (hCG, Sigma-Aldrich) 46-48 hours later. Pregnant females 398 were euthanized, and embryos collected in M2 media (MR-015-D, Sigma-Aldrich) at indicated 399 time points after hCG injection: E0.5, E1.0, E2.5 and E3.5. The sex of embryos was not 400 determined. Isolated embryos were fixed for $10 \mathrm{~min}$ in $4 \%$ Paraformaldehyde (Electron 401 Microscopy Sciences), permeabilized for 30 min in $0.3 \%$ Triton X-100 and 0.1M Glycine in PBS $1 \mathrm{X}$ 402 and blocked for 1 hour (1\% BSA, 0.1\% Tween in PBS 1X), followed by overnight incubation with 403 primary antibodies against CTCF (1:1000 dilution, ab188408, Abcam). Embryos were washed in 0.1\% Tween in PBS $1 \mathrm{X}$ and incubated with the appropriate secondary antibody for 1 hour at room temperature. Embryos were imaged using a Nikon Ti2-E microscope (Nikon Instruments)

406 equipped with a Yokogawa CSU-W1 spinning diskunit, a Photometrics BSI sCMOS camera and 20x 407 (N.A. 0.75) and 60x (N.A. 1.49) plan-apochromat objective lenses. Confocal z-stacks were 408 acquired and used to generate 3D surfaces were rendered based on nuclear DAPI-staining and 409 the corresponding regions were used to quantify the fluorescence intensity of CTCF. Embryo z410 stack images were quantified using Imaris Bitplane (Oxford Instruments). 


\section{Cell culture}

413 Wild-type (R1 and G4) ESC, ESC DUX and ESCCTCF-AID (ID: EN52.9.1) ${ }^{23}$ were grown on a feeder layer

414 of growth-arrested MEFs or on gelatin $0.1 \%$ in high-glucose DMEM (Invitrogen) supplemented

415 with 15\% FBS, 1:500 LIF (made in house), $0.1 \mathrm{mM}$ nonessential amino acids, 1\% glutamax, 1mM

416 Sodium Pyruvate, $55 \mathrm{mM} \beta$-mercaptoethanol, and 1\% penicillin/streptomycin (all from Life

417 Technologies) at $37^{\circ} \mathrm{C}$ and $5 \% \mathrm{CO}_{2}$. Cells were routinely passaged with Trypsin $0.05 \%$ (Gibco).

418 Media was changed every other day and passaged every 2-3 days. HEK293T (American Type

419 Culture Collection) cells were grown in DMEM, 10\% FBS, and 1\% penicillin/streptomycin.

420 Generation of infective lentiviral particles and ESC infections were performed as described ${ }^{35}$.

421 To generate ESC ${ }^{\text {DUX }}$ cell lines, a FLAG-tag version of the codon-optimized mouse DUX was

422 amplified by PCR (Primers in Extended Table 1) from pCW57.1-mDUX-CA (Addgene 99284) and

423 subcloned into the pBS31 plasmid (pBS31-FLAG_mDUX). A Flp-dependent recombination event

424 using pBS31-FLAG_mDUX in the KH2 ESC line was used to knock-in the cDNA for FLAG_mDUX

425 into a tetO-minimal promoter allocated in the Col1a1 locus as described ${ }^{11}$.

426 To generate additional ESC ${ }^{\text {CTCF-AID }}$ cell lines, R1 and ESC ${ }^{\text {DUX }}$ were co-transfected using jetPRIME

427 (PolyPlus transfection) with the plasmids CTCF-AID[71-114]-eGFP-FRT-Blast-FRT (92140,

428 Addgene), pCAGGS-Tir1-V5-BpA-Frt-PGK-EM7-NeoR-bpA-Frt-Rosa26 (92140, Addgene) and the

429 plasmid pX330-U6-Chimeric_BB-CBh-hSpCas9 (42330, Addgene) encoding sgRNAs targeting CTCF

430 and ROSA26 alleles (see Extended Table 1 for sgRNA sequences). Two days after transfection ESC

431 were selected with Neomycin $(200 \mathrm{ug} / \mathrm{ml})$ for one additional week. Individual ESC clones were

432 picked and amplified based on eGFP expression indicating successful CTCF targeting. HTI and 
433 western blot analyses were used to verify that eGFP and CTCF were lost upon addition of $500 \mu \mathrm{M}$

434 auxin for 24 hours.

435 To generate ESC lines carrying the LTR-RFP reporter, the LTR sequence was PCR amplified and 436 subcloned in a piggyBac plasmid upstream of a turboRFP (RFP) coding region to generate the LTR-

437 RFP reporter (Primers in Extended Table 1). PiggyBac-LTR-RFP plasmid together with a plasmid 438 encoding for a supertransposase were co-transfected in ESC and further selected with Neomycin

439 (200ug/ml) for one week. To generate ESC ${ }^{\text {CTCF-AID }}$ lines carrying a DOX-inducible ZSCAN4-PiggyBac

440 construct, the coding sequence for ZSCAN4C was amplified from cDNA and subcloned into the

441 plasmid PB-TRE-dCas9-VPR (63800, Addgene), after removing the dCas9-VPR insert. DOX-

442 inducible PiggyBac-ZSCAN4C plasmid together with a plasmid encoding for a supertransposase

443 were co-transfected in ESC and further selected with Hygromycin (200ug/ml) for one week. To

444 generate ZSCAN4-knockdown ESC CTCF-AID lines, cells were infected with pLKO.1 control or pLKO.1-

445 shZSCAN4 (5'-GAATGCAACAACTCTTGTAATCTCGAGATTACAAGAGTTGTTGCATTCT-3’, Millipore

446 Sigma) and further selected with Puromycin $(1 \mathrm{ug} / \mathrm{ml})$ for one week.

\section{Immunofluorescence}

449 Cells were fixed in 4 \% Paraformaldehyde (PFA, Electron Microscopy Sciences) for 10 min at RT

450 followed by 10 min of permeabilization using the following permeabilization buffer (100 mM Tris-

$451 \mathrm{HCl} \mathrm{pH} \mathrm{7.4,} 50 \mathrm{mM}$ EDTA pH 8.0, $0.5 \%$ Triton X-100). The following primary antibodies were

452 incubated overnight: OCT3/4 (1:100, sc-5279, Santa Cruz Biotechnology), ZSCAN4 (1:2000,

453 AB4340, Millipore Sigma), pH2AX (1:1000, 05-636, Millipore), CTCF (1:1000, ab188408, Abcam),

454 Flag (1:500, F1804, Sigma Aldrich). Corresponding Alexa-Fluor (-488, -568 and -647) secondary 
455 antibodies were used to reveal primary antibody binding (Thermo Fisher Scientific). For

456 generating the plots shown in Figure 1d, image analysis was performed using a custom Python

457 script. In brief, DAPI-stained nuclei were segmented using the StarDist deep-learning image

458 segmentation ${ }^{36}$. Segmented nuclei ROIs were used to quantify total DAPI intensity and RFP mean

459 intensity.

461 High throughput imaging (HTI)

462 A total of 10,000-20,000 ESC (depending on the experiment and on the specific ESC line) were

463 plated on gelatinized $\mu$ CLEAR bottom 96-well plates (Greiner Bio-One, 655087). ESC were treated

464 with DOX (different concentrations in the range from 150-600 ng/ml) or $500 \mu \mathrm{M}$ auxin as

465 indicated or incubate with $10 \mu \mathrm{M}$ EdU (Click Chemistry Tools) for 30 minutes before fixation with

466 4\% PFA in PBS for 10 minutes at room temperature. $\mathrm{yH} 2 \mathrm{AX}$ and ZSCAN4 staining was performed

467 using standard procedures. EdU incorporation was visualized using Alexa Fluor 488-azide or Alexa

468 Fluor 647-azide (Click Chemistry Tools) Click-iT labeling chemistry and DNA was stained using

469 DAPI (4',6-diamidino-2-phenylindole). When indicated, ESC ${ }^{\text {DUX }}$ were treated with $1 \mu$ M ATR

470 inhibitor (AZ20, Selleckchem).

471 Cooperation between CTCF-depletion and DUX expression was examined in CTCF-AID targeted

472 ESC $^{\text {DUX }}$ upon treatment with auxin and low concentration of DOX. Similarly, Cooperation between

473 CTCF-depletion and HDAC inhibition was examined in ESC ${ }^{\text {CTCF-AID }}$ treated with auxin and $10 \mu \mathrm{M}$

474 HDAC inhibitor.

475 Images were automatically acquired using a CellVoyager CV7000 high throughput spinning disk

476 confocal microscope (Yokogawa, Japan). Each condition was performed in triplicate wells and at 
477 least 9 different fields of view (FOV) were acquired per well. High-Content Image (HCI) analysis

478 was performed using the Columbus software (PerkinElmer). In brief, nuclei were first segmented

479 using the DAPI channel. Mean fluorescence intensities for $\mathrm{YH} 2 \mathrm{AX}$, ZSCAN4, CTCF, eGFP or RFP

480 signal were calculated over the nuclear masks in their respective channels. Single cell data

481 obtained from the Columbus software was exported as flat tabular .txt files, and then analyzed

482 using RStudio version 1.2.5001, and plotted using Graphpad Prism version 9.0.0.

\section{$484 \quad$ Live Cell imaging}

485 When indicated, ESC were infected with a lentiviral plasmid encoding H2B-GFP (kind gift from

Marcos Malumbres, CNIO, Spain). A total of 40,000 ESC were plated in gelatine-coated $\mu$-Slide 8

487 wells plates (80826, Ibidi) and imaged untreated or Auxin/DOX-treated for a time period between

488 43-48hrs depending on the experiment. Images were acquired every 15 or 20 minutes over the

489 time course using either a Nikon spinning disk confocal microscope or a Zeiss LSM780 confocal

490 microscope equipped with 20x plan-apochromat objective lenses (N.A. 0.75 and 0.8, respectively)

491 and stage top incubators to maintain temperature, humidity and CO2 (Tokai Hit STX and Okolab

492 Bold Line, respectively).

494 Western blot

495 Trypsinized cells were lysed in $50 \mathrm{mM}$ Tris pH 8, $8 \mathrm{M}$ Urea (Sigma) and 1\% Chaps (Millipore)

496 followed by 30 min of shaking at $4^{\circ} \mathrm{C} .20 \mu \mathrm{g}$ of supernatants were run on $4 \%-12 \%$ NuPage Bis-Tris

497 Gel (Invitrogen) and transferred onto Nitrocellulose Blotting Membrane (GE Healthcare).

498 Membranes were incubated with the following primary antibodies overnight at $4^{\circ} \mathrm{C}: \mathrm{p}-\mathrm{KAP} 1$ 
499 (dilution 1:1000, A300-767A, Bethyl) or ZSCAN4C (1:500, AB4340, Millipore Sigma), yH2AX

500 (1:1000, 05-636, Millipore), CTCF (1:1000, 07-729, Millipore), Flag (1:1000, F1804, Sigma Aldrich),

501 Tubulin (1:50000, T9026, Sigma-Aldrich). The next day the membranes were incubated with HRP-

502 conjugated secondary antibodies (1:5000) for $1 \mathrm{~h}$ at room temperature. Membranes were

503 developed using SuperSignal West Pico PLUS (Thermo Scientific).

$505 \quad$ Flow cytometry and cell sorting

506 For live cell flow cytometry experiments, cells were dissociated into single cell suspensions and

507 analyzed for RFP expression, DAPI was added to detect cells with compromised membrane

508 integrity. For EdU Click-IT experiments, cells were incubated for 20 min with $10 \mu \mathrm{M}$ EdU, fixed in

$5094 \%$ paraformaldehyde, permeabilized in $0.5 \%$ triton X-100, followed by Alexa Flour 488 -azide or

510 Alexa Flour 647-azide Click-iT labeling chemistry. DNA content was stained using DAPI or Hoechst

51133342 (62249, Thermo Fisher Scientific). Analytic flow profiles were recorded on a LSRFortessa

512 (BD Biosciences) or a FACSymphony A5 instrument (BD Biosciences). Data was analyzed using

513 FlowJo Version 10.7.1. Cell sorting experiments were performed on a BD FACSAria Fusion

514 instrument. Post-sort quality control was performed for each sample.

516 RNA extraction, cDNA synthesis and qPCR

517 Total RNA was isolated using Isolate II RNA Mini Kit (Bioline). cDNA was synthesized using

518 SensiFAST cDNA Synthesis Kit (Bioline). Quantitative real time PCR was performed with iTaq

519 Universal SYBR Green Supermix (BioRad) in a CFX96 Touch BioRad system. Expression levels were

520 normalized to GAPDH. For a primer list see Extended Table 1. 


\section{CUT\&RUN protocol}

523 The CUT\&RUN protocol was slightly modified as described ${ }^{37,38}$. In brief, trypsinized or cell sorted

524 ESC (between 150,000-500,000 cells depending on the experiment) were washed three times

525 with Wash Buffer (20 mM HEPES-KOH pH 7.5, $150 \mathrm{mM} \mathrm{NaCl}, 0.5 \mathrm{mM}$ spermidine, Roche complete

526 Protease Inhibitor tablet EDTA free) and bound to activated Concanavalin A beads (Polysciences)

527 for 10 minutes at room temperature. Cells were then permeabilized in Digitonin Buffer (0.05\%

528 Digitonin and 0.1\% BSA in Wash Buffer) and incubated with the antibody against CTCF (07-729,

529 Millipore) at $4^{\circ} \mathrm{C}$ for 2 hours. For negative controls, Guinea Pig anti-Rabbit IgG (ABIN101961,

530 Antibodies-online) was used. Cells were washed with Digitonin Buffer following antibody

531 incubation, and further incubated with purified hybrid protein A-protein G-Micrococcal nuclease

532 (pAG-MNase) at $4^{\circ} \mathrm{C}$ for 1 hour. Samples were washed in Digitonin Buffer, resuspended in $150 \mu \mathrm{l}$

533 Digitonin Buffer and equilibrated to $0^{\circ} \mathrm{C}$ on ice water for 5 minutes. To initiate MNase cleavage,

$5343 \mu \mathrm{l} 100 \mathrm{mM} \mathrm{CaCl}_{2}$ was added to cells and after 1 hour of digestion, reactions were stopped with

535 the addition of $150 \mu \mathrm{l}$ 2x Stop Buffer (340 mM NaCl, 20 mM EDTA, 4 mM EGTA, 0.02 \% Digitonin,

$53650 \mu \mathrm{g} / \mathrm{ml}$ RNase A, $50 \mu \mathrm{g} / \mathrm{ml}$ Glycogen). Samples were incubated at $37^{\circ} \mathrm{C}$ for 10 minutes to

537 release DNA fragments and centrifuged at $16,000 \mathrm{~g}$ for 5 minutes. Supernatants were collected

538 and a mix of $1.5 \mu \mathrm{l} 20 \%$ SDS / $2.25 \mu \mathrm{l} 20 \mathrm{mg} / \mathrm{ml}$ Proteinase $\mathrm{K}$ was added to each sample and

539 incubated at $65^{\circ} \mathrm{C}$ for 35 minutes. DNA was precipitated with ethanol and sodium acetate and

540 pelleted by high-speed centrifugation at $4^{\circ} \mathrm{C}$, washed, air-dried and resuspended in $10 \mu 0.1 \times$ TE. 
543 The entire precipitated DNA obtained from CUT\&RUN was used to prepare Illumina compatible

544 sequencing libraries. In brief, end-repair was performed in $50 \mu$ of T4 ligase reaction buffer,

$5450.4 \mathrm{mM}$ dNTPs, $3 \mathrm{U}$ of T4 DNA polymerase (NEB), $9 \mathrm{U}$ of T4 Polynucleotide Kinase (NEB) and $1 \mathrm{U}$

546 of Klenow fragment (NEB) at $20^{\circ} \mathrm{C}$ for 30 minutes. End-repair reaction was cleaned using AMPure

547 XP beads (Beckman Coulter) and eluted in $16.5 \mu \mathrm{l}$ of Elution Buffer (10 mM Tris- $\mathrm{HCl} \mathrm{pH} 8.5)$

548 followed by A-tailing reaction in $20 \mu \mathrm{l}$ of dA-Tailing reaction buffer (NEB) with $2.5 \mathrm{U}$ of Klenow

549 fragment exo- (NEB) at $37^{\circ} \mathrm{C}$ for 30 minutes. The $20 \mu$ of the A-tailing reaction were mixed with

550 Quick Ligase buffer 2X (NEB), $3000 \mathrm{U}$ of Quick Ligase (NEB) and $10 \mathrm{nM}$ of annealed adaptor

551 (Illumina truncated adaptor) in a volume of $50 \mu \mathrm{l}$ and incubated at room temperature for $20 \mathrm{~min}$.

552 The adaptor was prepared by annealing the following HPLC-purified oligos: 5'-

553 Phos/GATCGgAAGAGCACACGTCT-3' and 5'-ACACTCTTTCCCTACACGACGCTCTTCCGATC*T-3'

554 (*phosphorothioate bond). Ligation was stopped by adding $50 \mathrm{mM}$ of EDTA, cleaned with AMPure

555 XP beads and eluted in $14 \mu$ l of Elution Buffer. All volume was used for PCR amplification in a

$55650 \mu \mathrm{l}$ reaction with $1 \mu \mathrm{M}$ primers TruSeq barcoded primer p7, 5'-

CAAGCAGAAGACGGCATACGAGATXXXXXXXXGTGACTGGAGTTCAGACGTGTGCTCTTCCGATC*T-3’

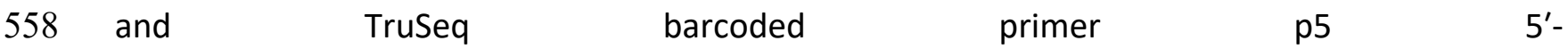

559 AATGATACGGCGACCACCGAGATCTACACXXXXXXXXACACTCTTTCCCTACACGACGCTCTTCCGATC*T-

$560 \quad 3^{\prime}$ (* represents a phosphothiorate bond and XXXXXXXX a barcode index sequence), and 2X Kapa

561 HiFi HotStart Ready mix (Kapa Biosciences). The temperature settings during the PCR

562 amplification were $45 \mathrm{~s}$ at $98^{\circ} \mathrm{C}$ followed by 15 cycles of $15 \mathrm{~s}$ at $98^{\circ} \mathrm{C}, 30 \mathrm{~s}$ at $63^{\circ} \mathrm{C}, 30 \mathrm{~s}$ at $72^{\circ} \mathrm{C}$

563 and a final 5 min extension at $72^{\circ} \mathrm{C}$. PCR reactions were cleaned with AMPure XP beads (Beckman

564 Coulter), run on a $2 \%$ agarose gel and a band of $300 \mathrm{bp}$ approximately was cut and gel purified 
565 using QIAquick Gel Extraction Kit (QIAGEN). Library concentration was determined with KAPA

566 Library Quantification Kit for Illumina Platforms (Kapa Biosystems). Sequencing was performed

567 on the Illumina NextSeq550 (75bp pair-end reads).

568

569 Cut\&Run data processing

570 Data were processed using a modified version of Cut\&RunTools ${ }^{39}$. Reads were adapter trimmed

571 using fastp v.0.20.040. An additional trimming step was performed to remove up to $6 \mathrm{bp}$ adapter

572 from each read. Next, reads were aligned to the $\mathrm{mm} 10$ genome using bowtie ${ }^{40}$ with the

573 'dovetail' and 'sensitive' settings enabled. Alignments were further divided into $\leq 120-b p$ and

$574>120-$ bp fractions. macs $2^{41}$ was used to call peaks with q-value cutoff $<0.01$. Normalized (RPKM)

575 signal tracks were generated using the 'bamCoverage' utility from deepTools with parameters

576 bin-size $=25$, smooth length $=75$, and 'center_reads' and 'extend_reads' options enabled ${ }^{42}$.

578 Processing for published ChIP datasets

579 Reads were aligned to the $\mathrm{mm} 10$ genome using bowtie $2^{40}$. Duplicate reads were removed using

580 MarkDuplicates from the Picard toolkit ("Picard Toolkit." 2019. Broad Institute, GitHub

581 Repository. http://broadinstitute.github.io/picard/). Normalized (RPKM) signal tracks were

582 generated bamCoverage utility from deepTools ${ }^{43}$, using the parameters bin-size $=25$, smooth

583 length=75, 'center_reads' and 'extend_reads'. For paired-end data, read mates were extended

584 to the fragment size defined by the two read mates. For single-end ChIP-seq data, reads were

585 extended to the estimated fragment length estimated by phantompeakqualtools ${ }^{44}$. 


\section{RNAseq data processing and batch correction}

588 Fastq files for RNAseq experiments ${ }^{5,23}$ were downloaded from SRA. RNAseq reads were adapter

589 trimmed using fastp v.0.20.0 (Chen et al., 2018). Transcript expression was quantified via

590 mapping to mouse gencode v25 transcripts using salmon (Patro et al., 2017). In order to

591 compare the two RNAseq experiments, batch correction was performed. Gene counts across

592 samples were quantile-normalized using the limma package ${ }^{44}$. Batch correction was then

593 performed on quantile-normalized counts using $\mathrm{COMBAT}^{45}$. Gene association was performed by

594 using GREAT (http://great.stanford.edu/public/html/) using "single nearest gene" by default

$5951000 \mathrm{~kb}$ distance.

597 ENDseq

598 END-seq was performed as described ${ }^{47}$. Briefly, for untreated DOX-treated ESC ${ }^{\text {DUX }}$, a total of 30 599 million cells in single cell suspension were embedded in a single agarose plug. Lysis and digestion 600 of embedded cells was performed using Proteinase $\mathrm{K}\left(50^{\circ} \mathrm{C}, 1\right.$ hour then $37^{\circ} \mathrm{C}$ for 7 hours $)$. 601 Agarose plugs were rinsed in TE buffer and treated with RNase $A$ at $37^{\circ} \mathrm{C}, 1$ hour. Next, DNA ends 602 were blunted. For these reactions, DNA was retained in the plugs to prevent shearing. The first 603 blunting reaction was performed using ExoVII (NEB, M0379S) for 1hr, 37C. Plugs were washed 604 twice in NEB Buffer 4 (1X), immediately followed by the second blunting reaction using ExoT (NEB, $605 \mathrm{M} 265 \mathrm{~S})$ for 1 hour, $24^{\circ} \mathrm{C}$. After this final blunting, two washes were performed in NEBNext dA606 Tailing Reaction Buffer (NEB, B6059S), followed by A-tailing (Klenow 3'- > 5' exo-, NEB, M0212S).

607 After A-tailing, we performed a ligation with the "END-seq hairpin adaptor 1," listed in reagents 608 section, using NEB Quick Ligation Kit (NEB, M2200S). 


\section{DNA sonication, End-Repair, A-tailing, and Library Amplification}

611 Agarose plugs were then melted and dissolved. DNA was sonicated using to a median shear

612 length of $170 \mathrm{bp}$ using a Covaris S220 sonicator for 4 min at $10 \%$ duty cycle, peak incident power

613175,200 cycles per burst, $4^{\circ} \mathrm{C}$. Following the sonication, DNA was precipitated with ethanol and

614 dissolved in $70 \mu \mathrm{ITE}$ buffer. $35 \mu \mathrm{L}$ of Dynabeads were washed twice with $1 \mathrm{~mL}$ Binding and Wash

615 Buffer (1xBWB) (10 mM Tris-HCl pH8.0, 1 mM EDTA, $1 \mathrm{M} \mathrm{NaCl}$, 0.1\% Tween20). After the wash,

616 beads were recovered using a DynaMag-2 magnetic separator (12321D, Invitrogen) and

617 supernatants were discarded. Washed beads were resuspended in $130 \mu \mathrm{L} 2$ XBWB (10 mM Tris-

$618 \mathrm{HCl}$ pH8.0, $2 \mathrm{mM}$ EDTA, $2 \mathrm{M} \mathrm{NaCl}$ ) combined with the $130 \mu \mathrm{L}$ of sonicated DNA followed by an

619 incubation at $24^{\circ} \mathrm{C}$ for $30 \mathrm{~min}$. Next, the supernatant was removed, and the biotinylated DNA

620 bound to the beads was washed thrice with $1 \mathrm{~mL} 1 \mathrm{xBWB}$, twice with $1 \mathrm{~mL} E B$ buffer, once with

$6211 \mathrm{~mL}$ T4 ligase reaction buffer (NEB) and then resuspended in $50 \mu \mathrm{L}$ of end-repair reaction mix

622 (0.4 mM of dNTPs, $2.7 \mathrm{U}$ of T4 DNA polymerase (NEB), $9 \mathrm{U}$ of T4 Polynucleotide Kinase (NEB) and

$6231 \mathrm{U}$ of Klenow fragment (NEB)) and incubated at $24^{\circ} \mathrm{C}$ for $30 \mathrm{~min}$. Once again, the supernatant

624 was removed using a magnetic separator and beads were then washed once with $1 \mathrm{~mL} 1 \mathrm{xBWB}$,

625 twice with $1 \mathrm{~mL}$ EB buffer, once with $1 \mathrm{~mL}$ NEBNext dA-Tailing reaction buffer (NEB) and then

626 resuspended in $50 \mu \mathrm{L}$ of with NEBNext dA-Tailing reaction buffer (NEB) and $20 \mathrm{U}$ of Klenow

627 fragment exo- (NEB). The A-tailing reaction was incubated at $37^{\circ} \mathrm{C}$ for $30 \mathrm{~min}$. The supernatant

628 was removed using a magnetic separator and washed once with $1 \mathrm{~mL}$ NEBuffer 2 and

629 resuspended in $115 \mathrm{~mL}$ of Ligation reaction with Quick Ligase buffer (NEB), 6,000 U of Quick

630 Ligase (NEB) and ligated to "END-seq hairpin adaptor 2" by incubating the reaction at $25^{\circ} \mathrm{C}$ for 
$63130 \mathrm{~min}$. Reaction was stopped by adding $50 \mathrm{mM}$ of EDTA, and beads washed 3X BWB, 3X EB, and

632 eluted in $8 \mu \mathrm{L}$ of EB. Hairpin adaptors were digested using USER enzyme (NEB, M5505S) at 37C

633 for 30 minutes. PCR amplification was performed in $50 \mu \mathrm{L}$ reaction with $10 \mathrm{mM}$ primers $5^{\prime}$ -

634 CAAGCAGAAGACGGCATACGA-GATXXXXXXGTGACTGGAGTTCAGACGTGTGCTCTTCCGATC*T-3'

635 and 5'-AATGATACGGCGACCACCGAGATCTACACTCTTTCCCTACACGACGCTCTTCCGATC*T-3', and

636 2X Kapa HiFi HotStart Ready mix (Kapa Biosciences). * represents a phosphothioratebond and

637 NNNNNN a Truseq index sequence. PCR program: $98^{\circ} \mathrm{C}, 45 \mathrm{~s} ; 15$ cycles $\left[98^{\circ} \mathrm{C}, 15 \mathrm{~s} ; 63^{\circ} \mathrm{C}, 30 \mathrm{~s}\right.$;

$\left.63872^{\circ} \mathrm{C}, 30 \mathrm{~s}\right] ; 72^{\circ} \mathrm{C}, 5 \mathrm{~min}$. PCR reactions were cleaned with AMPure XP beads, and after running

639 the reactions on a $2 \%$ agarose gel, $200-500 \mathrm{bp}$ fragments were isolated. Libraries were purified

640 using QIA-quick Gel Extraction Kit (QIAGEN). Library concentration was determined with KAPA

641 Library Quantification Kit for Illumina Platforms (Kapa Biosystems) and the sequencing was

642 performed on Illumina NextSeq 500 or 550 (75bp single end reads).

\section{Processing of ENDseq data}

645 END-seq reads were aligned to the mouse reference genome mm10 using bowtie (v1.1.2) $)^{41}$ 646 (PMID: 19261174) with parameters -n 3 -I 50 -k 1. Functions "view" and "sort" of samtools (v 1.6)

647 (PMID: 19505943) were used to convert and sort the aligned sam files to sorted bam files. Bam

648 files were further converted to bed files by bedtools bamToBed command (PMID: 20110278).

649 END-seq peaks were called by MACS (v1.4.3) ${ }^{42}$ with parameters --nolambda --nomodel --keep-

650 dup=all (PMID: 18798982) and peaks within blacklisted regions

651 (https://sites.google.com/site/anshulkundaje/projects/blacklists) were filtered out (PMID:

652 31249361). Overlapped peaks from two independent clones were used in this paper. 


\section{SUPPLEMENTARY REFERENCES:}

35 Ruiz, S., Panopoulos, A.D., Herrerías, A., Bissig, K.D., Lutz, M., Berggren, W.T., Verma, I..M and

656 Izpisua Belmonte, J.C. A high proliferation rate is required for cell reprogramming and 657 maintenance of human embryonic stem cell identity. Curr. Biol. 21, 45-52 (2011).

65936 Weigert, M., Schmidt, U., Haase, R., Sugawara, K. and Myers, G. Star-convex Polyhedra for 3D 660 Object Detection and Segmentation in Microscopy. Proceedings of the IEEE/CVF Winter 661 Conference on Applications of Computer Vision (WACV), 3666-3673 (2020).

662

66337 Skene, P.J. and Henikoff, S.. An efficient targeted nuclease strategy for high-resolution 664 mapping of DNA binding sites. Elife 6, e21856 (2017).

38 Meers, M.P., Bryson, T.D., Henikoff, J.G. and Henikoff, S. (2019). Improved CUT\&RUN

667 chromatin profiling tools. Elife 8, e46314 (2019).

668

66939 Zhu, Q., Liu, N., Orkin, S.H. and Yuan, G.C. CUT\&RUNTools: a flexible pipeline for CUT\&RUN

670 processing and footprint analysis. Genome Biol. 20, 192 (2019).

671

67240 Chen, S., Zhou, Y., Chen ,Y. and Gu, J. fastp: an ultra-fast all-in-one FASTQ preprocessor.

673 Bioinformatics 34, 884-890 (2018). 
67541 Langmead, B. and Salzberg, S.L. Fast gapped-read alignment with Bowtie 2. Nat. Methods 9, $676 \quad 357-9(2012)$.

677

67842 Zhang, Y., Liu, T., Meyer, C.A., Eeckhoute, J., Johnson, D.S., Bernstein, B.E., Nusbaum, C., 679 Myers, R.M., Brown, M., Li, W. and Liu, X.S. Model-based analysis of ChIP-Seq (MACS). Genome Biol. 9, R137 (2008).

43 Ramírez, F., Ryan, D.P., Grüning, B., Bhardwaj, V., Kilpert, F., Richter, A.S., Heyne, S., Dündar,

F., and Manke, T. deepTools2: a next generation web server for deep-sequencing data analysis.

Nucleic Acids Res 44, 160-165 (2016).

685

44 Kharchenko, P.V., Tolstorukov, M.Y. and Park, P.J. Design and analysis of ChIP-seq experiments for DNA-binding proteins. Nat. Biotechnol. 26, 1351-1359 (2008).

688

68945 Ritchie, M.E., Phipson, B., Wu, D., Hu, Y., Law, C.W., Shi, W. and Smyth, G.K. limma powers 690 differential expression analyses for RNA-sequencing and microarray studies. Nucleic Acids Res.

$691 \quad$ 43: e47 (2015).

69346 Johnson, W.E., Li, C. and Rabinovic, A. Adjusting batch effects in microarray expression data 694 using empirical Bayes methods. Biostatistics. 8: 118-127 (2007). 
bioRxiv preprint doi: https://doi.org/10.1101/2020.12.20.423692; this version posted December 22, 2020. The copyright holder for this preprint

(which was not certified by peer review) is the author/funder, who has granted bioRxiv a license to display the preprint in perpetuity. It is made available under aCC-BY-NC-ND 4.0 International license.

697 Resolution, and Genome-Wide Approach to Map DNA Double-Strand Breaks and Resection in

698 Human Cells. Methods Mol Biol. 2153: 9-31.

699

700

701

702

703

704

705

706

707

708

709

710

711

712

713

714

715

716

717 


\section{ACKNOWLEDGMENTS}

719 We thank Bechara Saykali and Pedro Rocha for critical reading of the manuscript, and to Jacob

720 Paiano for critical discussion. We are grateful to Christian Franke for the continuous technical

721 support on R. We also thank Pedro Rocha, Rafael Casellas and Seol Kyoung Jung for their help on

722 exploring HiC data. David Goldstein and the CCR Genomics Core for sequencing support and

723 Ferenc Livak and the CCR Flow cytometry Core for experimental support. Research in S.R.

724 laboratory is supported by the Intramural Research Program of the NIH. T.O. is supported by a 725 postdoctoral fellowship of the Helen Hay Whitney Foundation.

\section{AUTHOR CONTRIBUTIONS}

728 T.O. and S.R. conceived the study. T.O., M.V-S. designed, performed and analyzed experiments.

729 C.N.D. and M.F. provided technical support. D.T. and P.C.F. analyzed sequencing data. G.P. 730 provided support with high-throughput microscopy imaging. A.D.T. and M.J.K. analyzed confocal

731 microscopy data. E.L.D. and M.M.P. provided critical reagents. N.Z. performed ENDseq 732 experiments. W.W. analyzed ENDseq data. A.N. supervised ENDseq experiments. E.P.N. provided 733 critical reagents. S.R. supervised the study and wrote the manuscript with comments and help 734 from all authors.

737 The authors declare no competing interests. 
bioRxiv preprint doi: https://doi.org/10.1101/2020.12.20.423692; this version posted December 22, 2020. The copyright holder for this preprint

(which was not certified by peer review) is the author/funder, who has granted bioRxiv a license to display the preprint in perpetuity. It is made available under aCC-BY-NC-ND 4.0 International license.

\section{SUPPLEMENTARY INFORMATION}

741 Supplementary Information is available for this paper.

742

743 Correspondence and requests for materials should be addressed to Sergio Ruiz

744 (sergio.ruizmacias@nih.gov)

745

746 
a
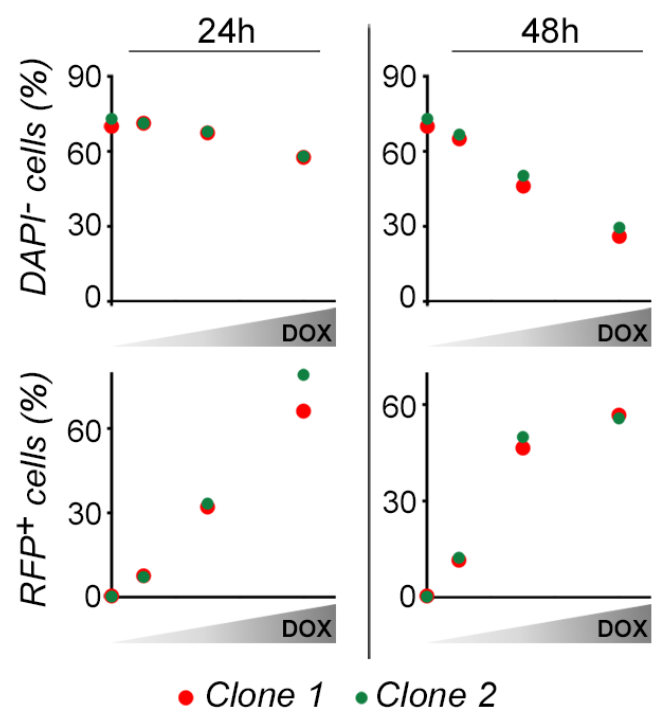

C

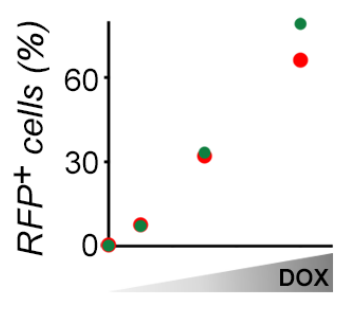

- Clone 1 - Clone 2

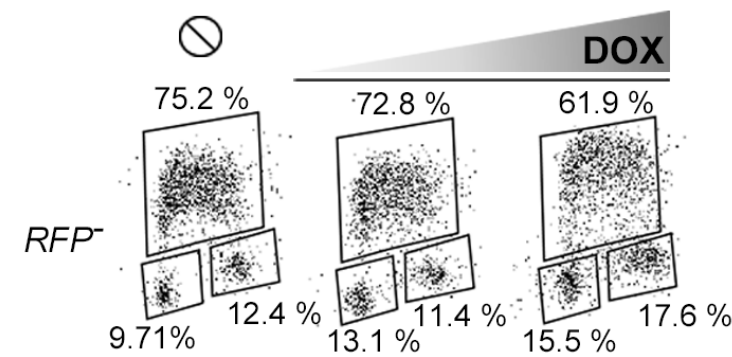

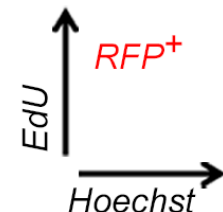

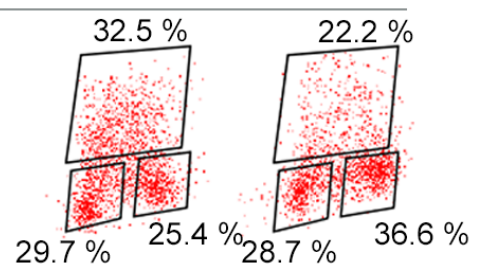

e

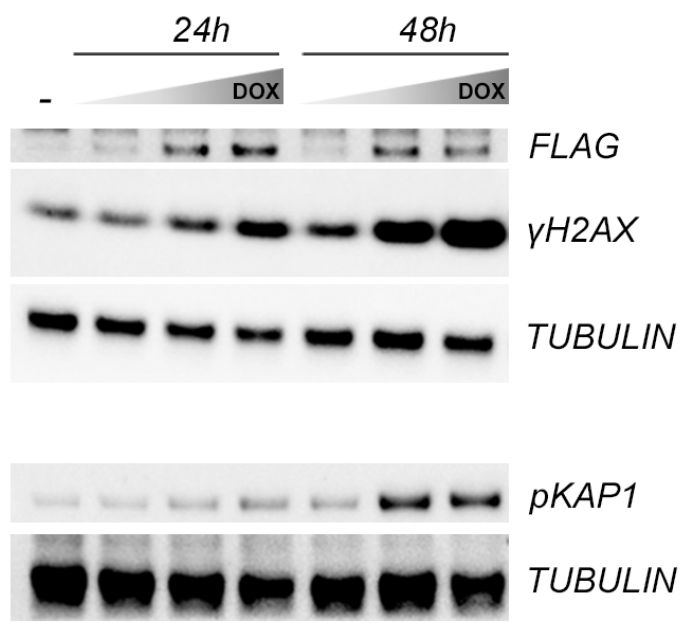

b

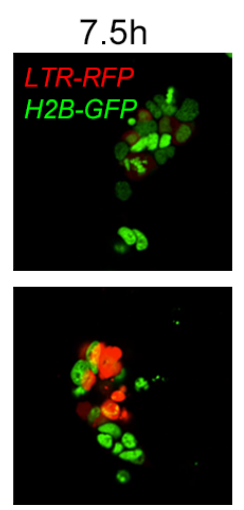

$22.5 \mathrm{~h}$

d
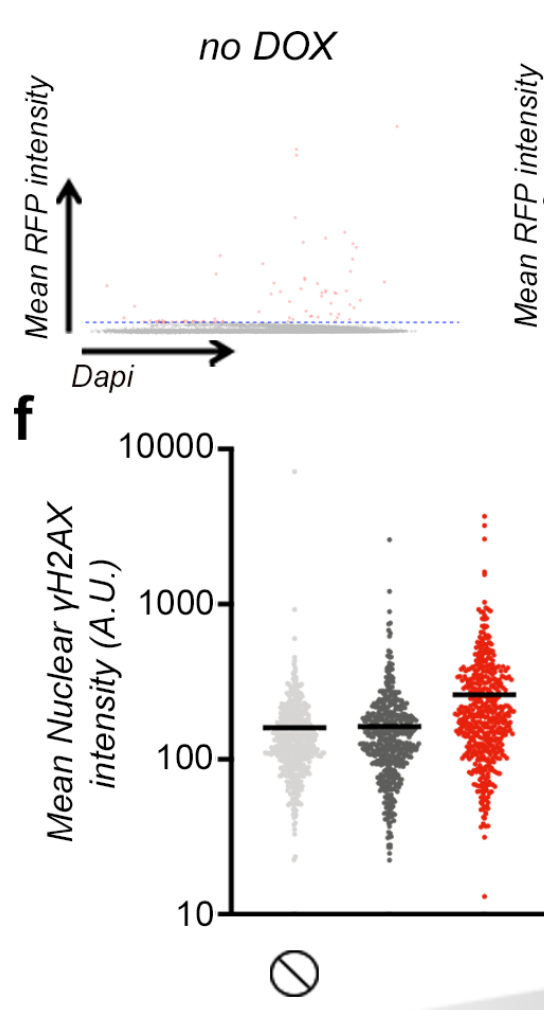

g

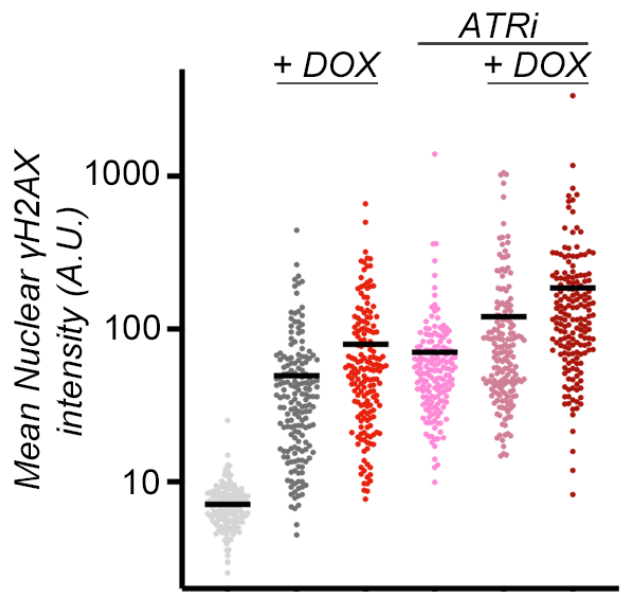

Figure 1 19.5h

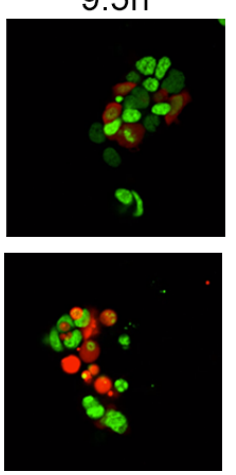

$12 \mathrm{~h}$

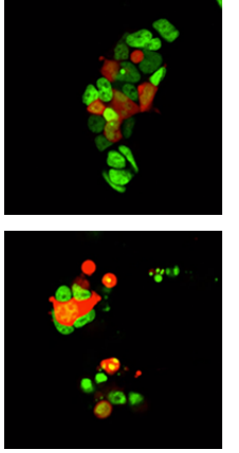

29h

$36 \mathrm{~h}$
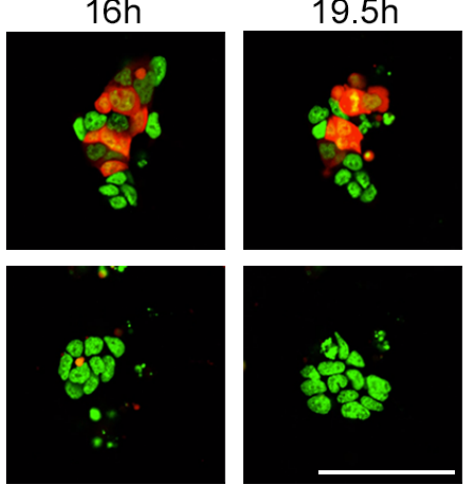

49h

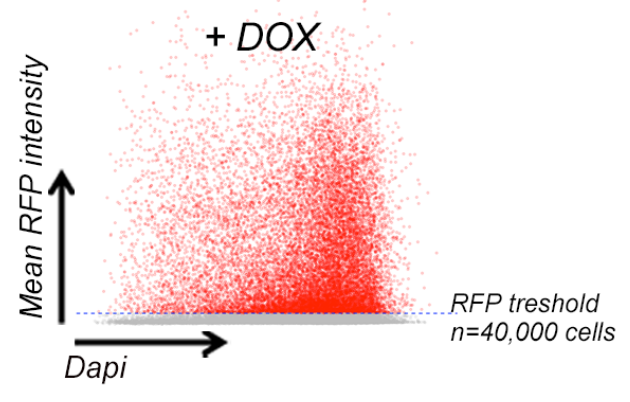

untreated

- RFP- cells

- RFP $^{+}$cells $n=500 \mathrm{ce} / \mathrm{s}$ 
Fig. 1: Induction of totipotent-like features in ESC correlated with DNA damage and cell death.

a, Plots showing the percentage of alive $\left(\mathrm{DAPI}^{-}\right)$and $\mathrm{RFP}^{+}$cells from $L T R-R F P$ reporter ESC ${ }^{\mathrm{DUX}}$ treated with increasing doses of $\operatorname{DOX}(150,300$ and $600 \mathrm{ng} / \mathrm{ml})$ for the indicated time points. Data was collected by flow cytometry. b, Representative images obtained from a time lapse experiment where LTR-RFP reporter ESC ${ }^{D U X}$ expressing H2B-eGFP were treated with DOX and imaged at the indicated timepoints. Scale bar, $100 \mu \mathrm{m}$. c, Flow cytometry analysis of the cell cycle distribution in untreated or DOX-treated $L T R-R F P$ reporter ESC ${ }^{D U X}$ for 24 hours. Percentages for each phase of the cell cycle are included. $\mathbf{d}$, Dot plots showing cell distribution based on DNA content and RFP expression in LTR-RFP reporter ESC DUX treated with DOX for 24 hours. e, Western blot analysis of the indicated proteins performed in ESC ${ }^{\text {DUX }}$ treated with different doses of DOX for the indicated time points. Expression of DUX was monitored by its FLAG-tag. Tubulin levels are shown as a loading control. f, High-throughput imaging (HTI) quantification of $\gamma \mathrm{H} 2 \mathrm{AX}$ in $L T R$ RFP reporter ESC $^{\mathrm{DUX}}$ treated with different concentrations of DOX for 24 hours. Center lines indicate mean values. $\varnothing=$ No treatment. $g, H T I$ quantification of $\gamma \mathrm{H} 2 \mathrm{AX}$ in $L T R-R F P$ reporter ESCDUX treated with DOX and/or with $1 \mu \mathrm{M}$ ATR inhibitor (ATRi) for 24 hours. Center lines indicate mean values. In (c), (f) and (g), cells were split in $\mathrm{RFP}^{-}$or $\mathrm{RFP}^{+}$. In (a-g) data are representative of at least two independent experiments performed in two different clones. 
a

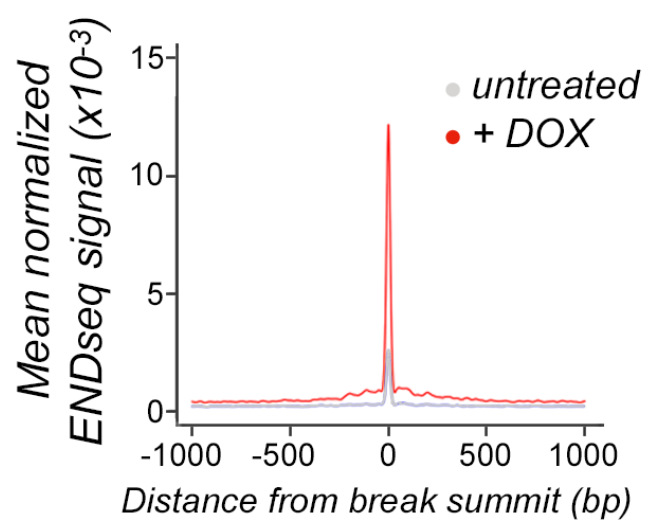

b

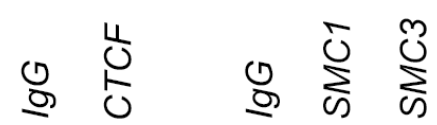

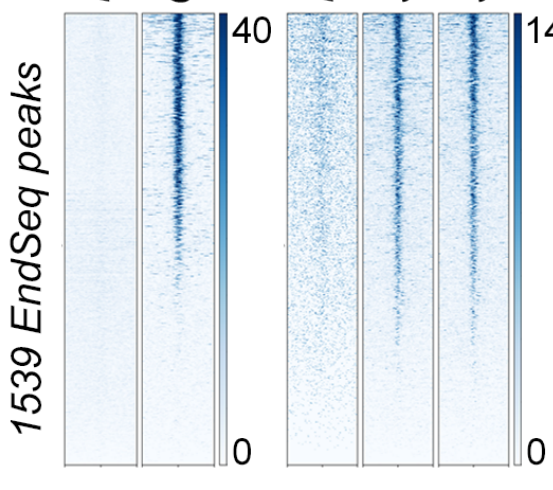

Figure 2

chr6:92,772,000-92,785,000 d

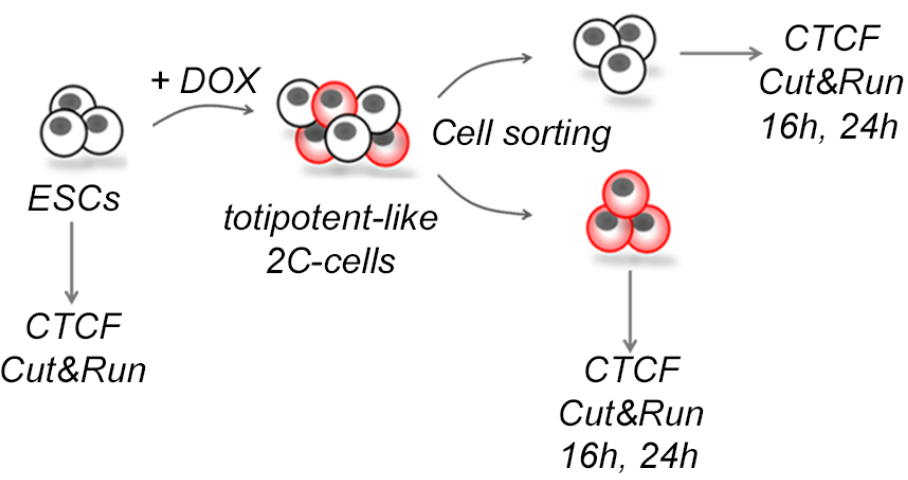

f

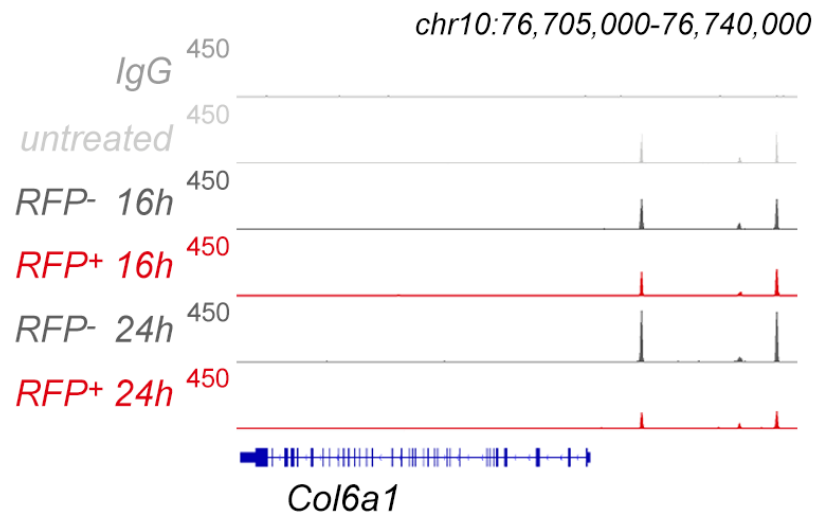

e

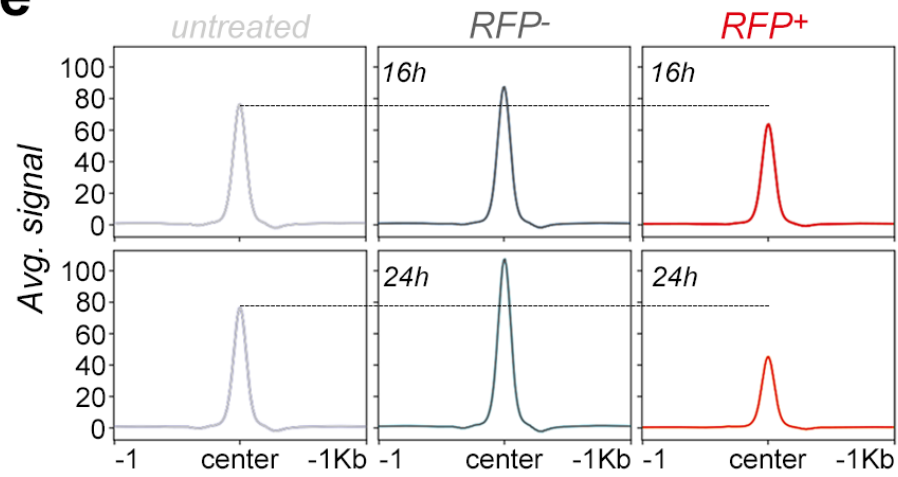

g

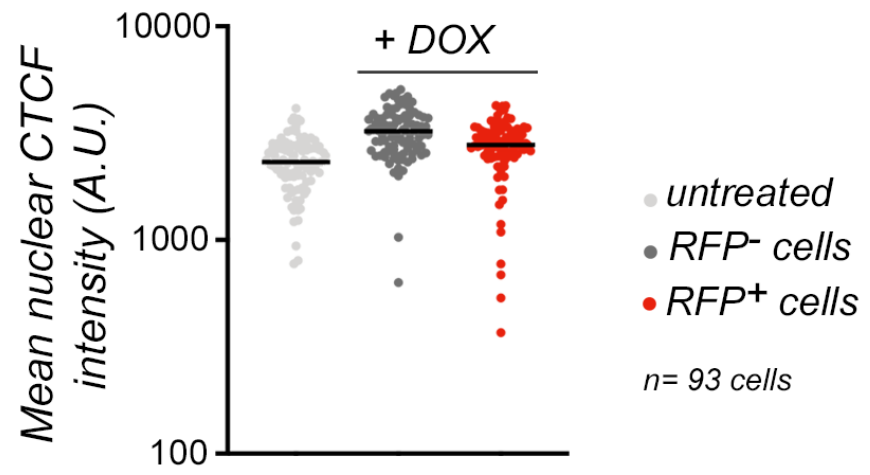


Fig. 2: 2C-like ESC are characterized by decreased levels of chromatin-bound CTCF. a, Plot showing aggregated ENDseq signal in untreated and DOX-treated ESC ${ }^{\text {DUX }}$ for 16 hours from one clonal line in the set of overlapped 1539 ENDseq sites identified in two independent DOX-treated ESC $^{\text {DUX }}$ clones. b, Heatmaps showing $\mathrm{CTCF}^{20}, \mathrm{SMC}^{2}$ and $\mathrm{SMC}^{21}$ occupancy at the set of 1539 ENDseq sites. c, Genome browser tracks showing ENDseq signal in untreated and DOX-treated $\mathrm{ESC}^{\mathrm{DUX}}$ at the indicated genome location. In addition, $\mathrm{CTCF}^{20}, \mathrm{SMC}$ and $\mathrm{SMC} 3^{21}$ occupancy in ESC is shown. ENDseq peak is highlighted. $\mathbf{d}$, Schematic representation of the experiment performed. e, Cut\&Run read density plot (RPKM) showing CTCF occupancy in the set of 50183 CTCF sites identified in $\mathrm{ESC}^{20}$ in the cell samples shown in (d). The signal obtained in corresponding inputs (IgG) was subtracted. f, Genome browser tracks showing CTCF occupancy at the indicated genome location in the cell samples shown in (d). $\mathbf{g}, \mathrm{HTI}$ quantification of CTCF in untreated or DOX-treated ESC ${ }^{\text {DUX }}$ for 24 hours. Cells were split into RFP+ ${ }^{+}$or RFP- subpopulations. Center lines indicate mean values. In (a) and (e-g) representative data from one ESC ${ }^{\text {DUX }}$ clone is shown but two independent clones were analyzed. In (b, c and f) input (IgG) is shown as a background reference control. 
a

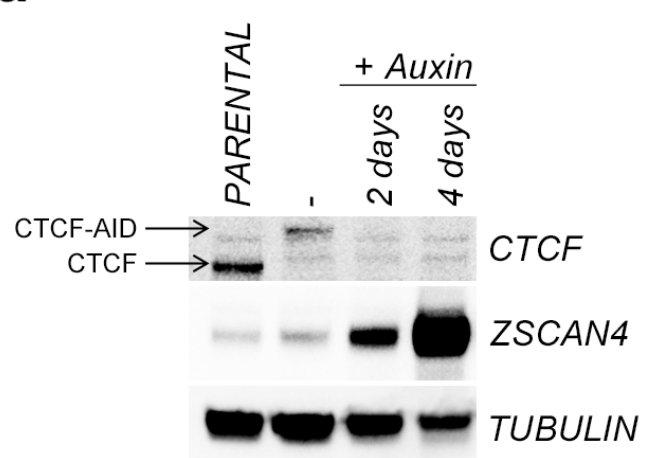

C

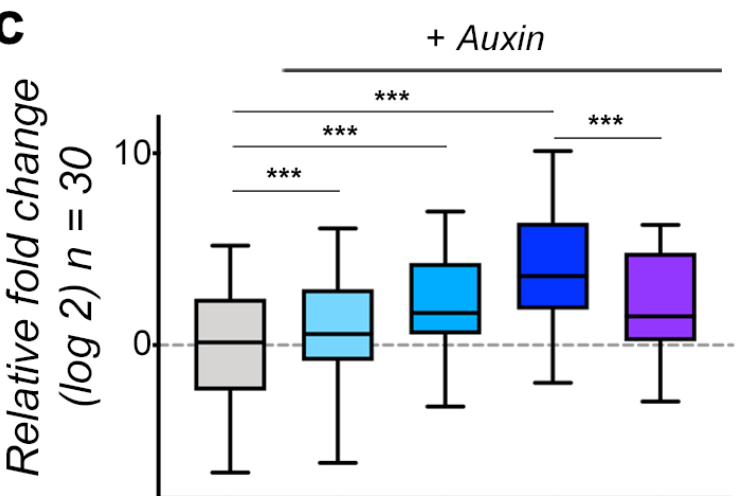

b

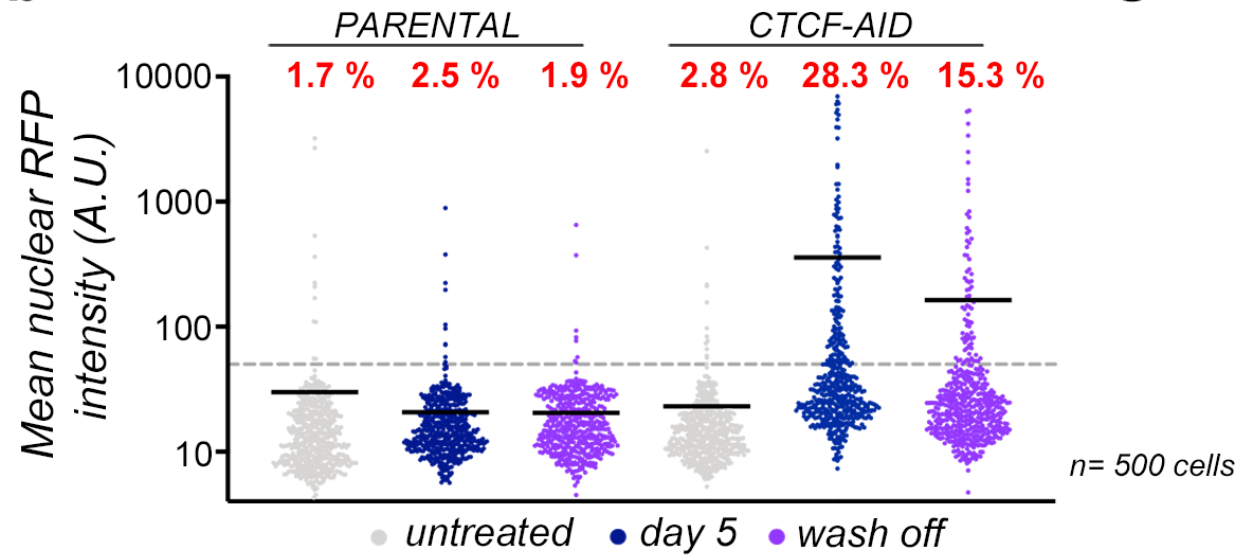

e

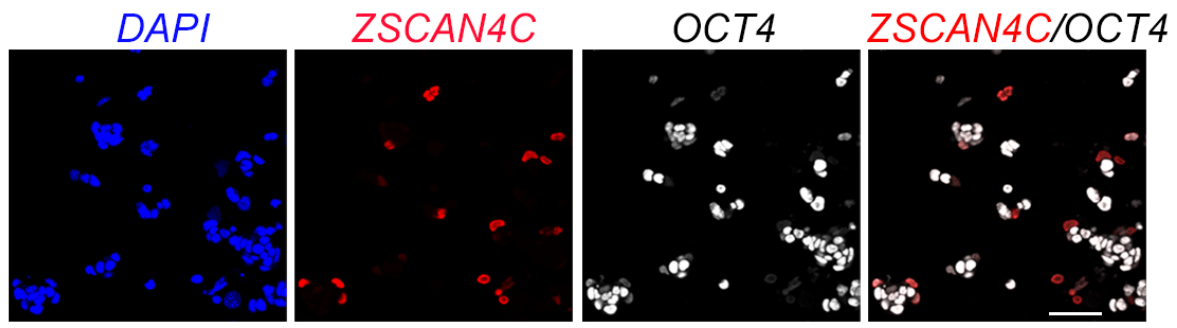

uuntreated uday 1 aday 2 day 4 awash off

d untreated

day 1

day 2

day 4 wash off

chr $4: 90,315,000-90,325,000$ [0-21]

\section{0-21]}

$[0-21]$

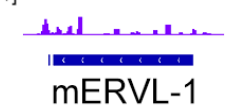

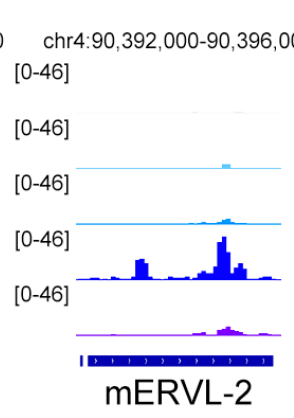

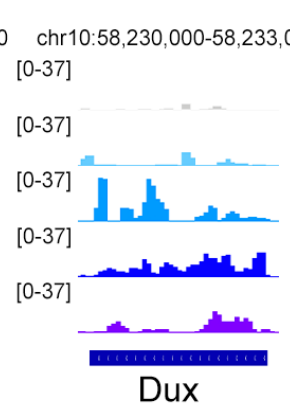

$52 \mathrm{~h}$
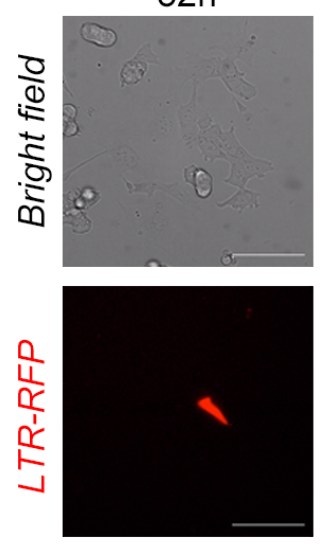

$68 \mathrm{~h}$
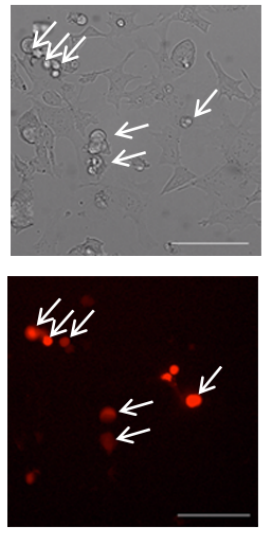

91h
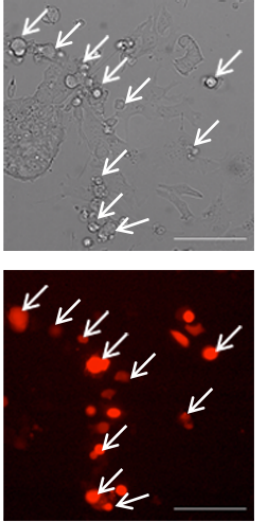

chr3:93,796,000-93,798,000 chr7:103,416,000-103,420,000 chr7:11,005,000-11,011,000 [0-43]

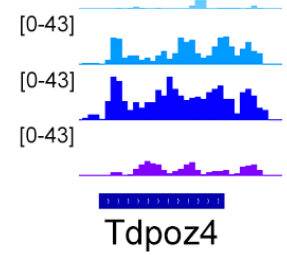

$[0-130]$

$[0-130]$
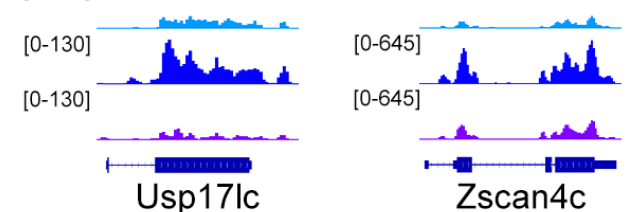

g

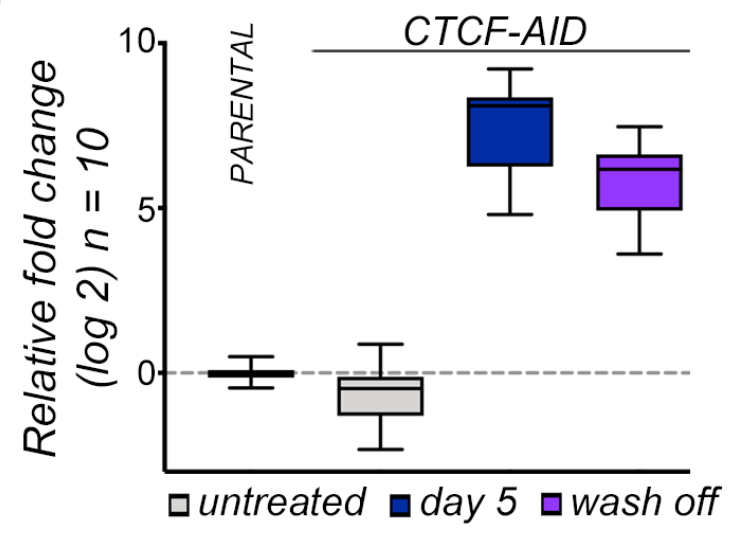


Figure 3: Spontaneous 2C-like conversion in CTCF-depleted ESC. a, Western blot analysis of the indicated proteins performed in ESC CTCF-AID treated with auxin for two and four days. Parental ESC were used to show the smaller size and higher levels of CTCF compared to ESC CTCF-AID. Tubulin levels are shown as a loading control. b, HTI quantification of $\mathrm{RFP}^{+}$cells in untreated or auxintreated for five days LTR-RFP reporter parental ESC and ESCCTCF-AID. RFP ${ }^{+}$cells two days after a wash off following three days of auxin treatment were also quantified. Center lines indicate mean values. Percentages of $\mathrm{RFP}^{+}$cells above the threshold are indicated. c, Graph showing the relative fold change ( $\log 2)$ expression of a subset of thirty $2 \mathrm{C}$ associated genes in ESC CTCF-AID treated with auxin for one, two and four days (Supplementary Table 7). Untreated and wash off ESC CTCF-AID were also included. Data was obtained from RNAseq datasets ${ }^{23}$. d, Genome browser tracks showing RNAseq RPKM read count at the indicated genes in the same samples as in (c). e) Immunofluorescence analysis of ZSCAN4 and OCT4 in ESC ${ }^{\text {CTCF-AID }}$ treated with auxin for 4 days. DAPI was used to visualize nuclei. Scale bars, $100 \mu \mathrm{m}$. f, Representative bright field images (upper panels) obtained from a time lapse experiment performed in ESC ${ }^{\text {CTCF-AID }}$ treated with auxin. RFP cells are shown as they convert over time (lower panels). Time since the addition of auxin is indicated. White arrows indicate $2 \mathrm{C}$ converted cells undergoing cell death. Scale bars, $100 \mu \mathrm{m} . \mathrm{g}$, Graph showing the relative fold change $(\log 2)$ expression of a subset of ten $2 \mathrm{C}$ associated genes (DUX, ZSCAN4, ZFP352, TCSTV3, SP110, TDPOZ1, DUB1, EF1a, PRAMEL7 and MERVLs) in LTR-RFP reporter ESC ${ }^{\text {CTCF-AID }}$ untreated or treated with auxin for three days and further incubated with auxin or washed off for additional 18 hours (a total of five days) and sorted based on RFP expression. Parental ESC were also sorted and included as a reference. GAPDH expression was 
bioRxiv preprint doi: https://doi.org/10.1101/2020.12.20.423692; this version posted December 22, 2020. The copyright holder for this preprint (which was not certified by peer review) is the author/funder, who has granted bioRxiv a license to display the preprint in perpetuity. It is made available under aCC-BY-NC-ND 4.0 International license.

used to normalize gene expression. In ( $\mathbf{a}, \mathbf{b}$ and $\mathbf{f})$, one representative experiment is shown but at least two independent experiments were performed. 
a

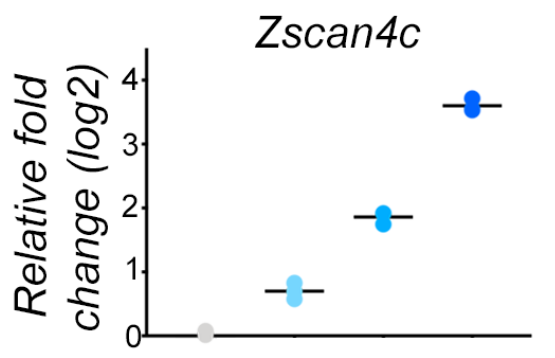

b

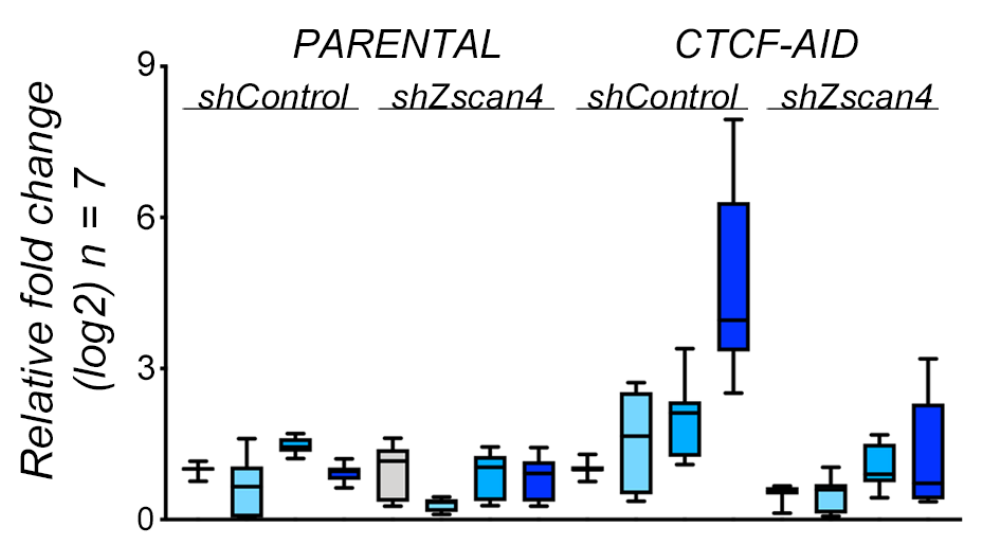

uuntreated aday 1 aday 2 aday 4
Dux

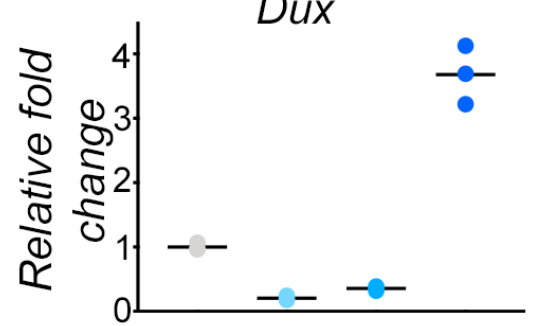

mERVL

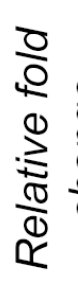

Figure 4

C

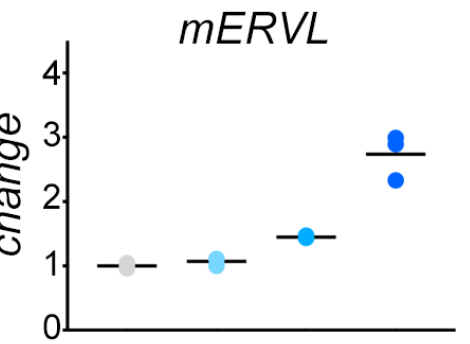

- untreated

- day 1

- day 2

- day 3

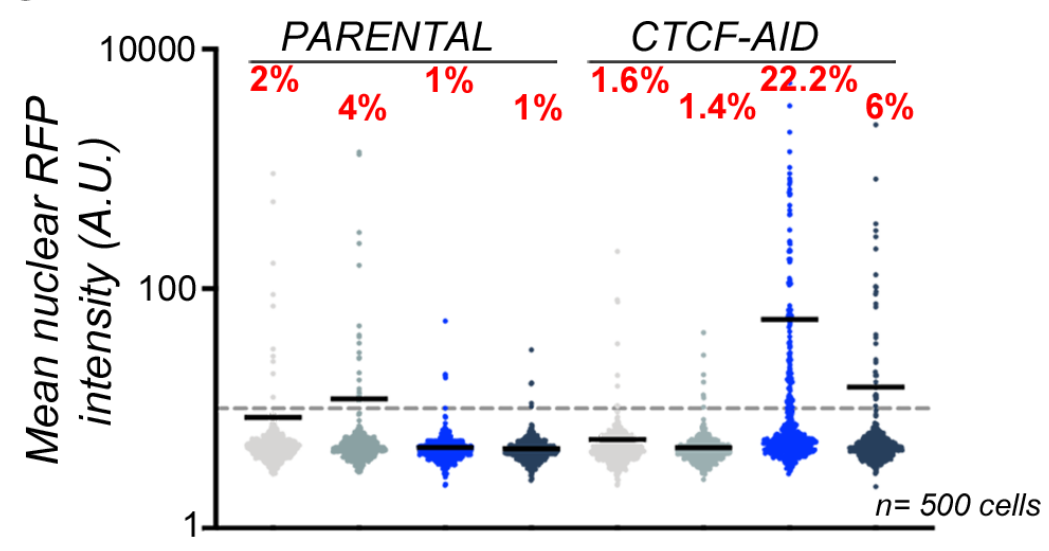

- untreated • shZscan4 • Auxin • shZscan4 + Auxin
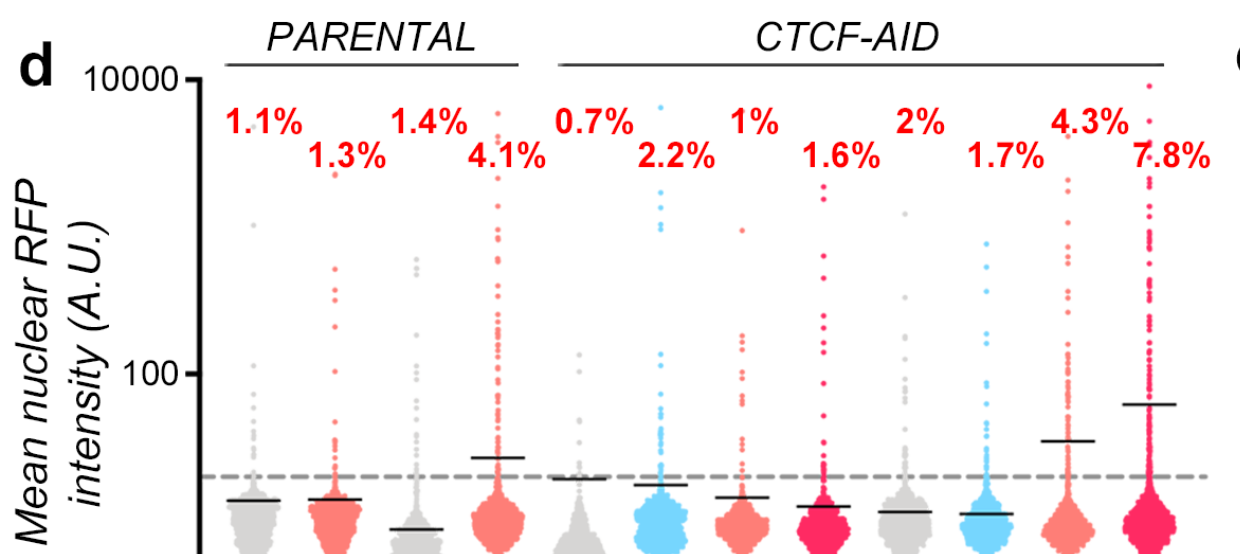

e

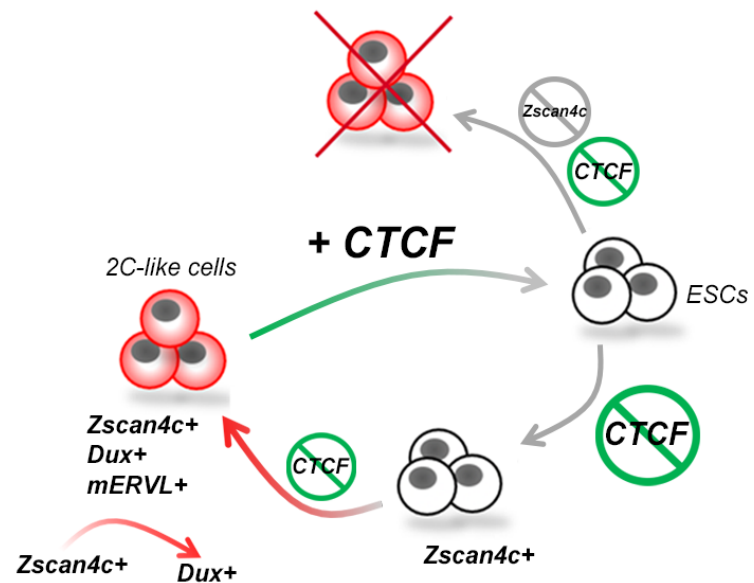

$\perp$

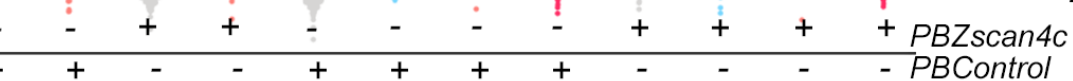

Zscan $4 c^{+} \quad{ }^{-}{ }^{-}+$

Zscan4c+

untreated $\bullet$ Auxin $\bullet$ DOX Auxin + DOX $n=1500$ cells 
Figure 4: Transcriptional activation of the ZSCAN4 cluster is required for 2C-like reprogramming. a, Graph showing the relative fold change (log2 or linear) expression of DUX, ZSCAN4 and MERVL in untreated or auxin-treated LTR-RFP reporter ESC ${ }^{\text {CTCF-AID }}$ for the indicated days. Data are shown by triplicate. b, Graph showing the averaged relative fold change (log2) expression of seven 2C genes (DUX, ZSCAN4, ZFP352, TCSTV3, SP110, TDPOZ1 and MERVLS) in untreated or auxin-treated at the indicated time points in LTR-RFP reporter control and ESC ${ }^{\text {CTCF- }}$ AID. ESC were infected with lentiviruses expressing control or shRNAs against ZSCAN4. Reactions were performed by triplicate in two independent experiments. c, HTI quantification of RFP ${ }^{+}$cells in untreated or auxin-treated for four days $L T R$-RFP reporter control and ESC CTCF-AID. ESC were infected with lentiviruses expressing control or shRNAs against ZSCAN4. Center lines indicate mean values. d, $\mathrm{HTI}$ quantification of $\mathrm{RFP}^{+}$cells in untreated or auxin-treated for 24 hours $L T R$ -

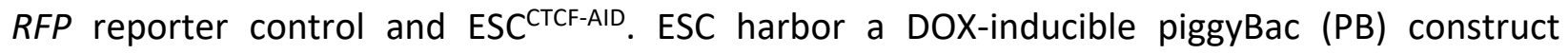
expressing ZSCAN4C and were induced as indicated together with auxin. Center lines indicate mean values. e, Schematic representation of the model inferred from the data presented here. In (a-d), one representative experiment is shown but at least two independent experiments were performed. In (c, d) percentages of $\mathrm{RFP}^{+}$cells above the threshold are indicated. 